Chapter 9

\title{
Modeling and Linear Programming in Engineering Management
}

\author{
William P. Fox and Fausto P. Garcia \\ Additional information is available at the end of the chapter \\ http://dx.doi.org/10.5772/54500
}

\section{Introduction}

Consider planning the shipment of needed items from the warehouses where they are manufactured and stored to the distribution centers where they are needed.

There are three warehouses at different cities: Detroit, Pittsburgh and Buffalo. They have 250, 130 and 235 tons of paper accordingly. There are four publishers in Boston, New York, Chicago and Indianapolis. They ordered 75, 230, 240 and 70 tons of paper to publish new books. There are the following costs in dollars of transportation of one ton of paper:

\begin{tabular}{ccccc}
\hline From I To & Boston (BS) & New York (NY) & Chicago (CH) & Indianapolis (IN) \\
\hline Detroit (DT) & 15 & 20 & 16 & 21 \\
\hline Pittsburgh (PT) & 25 & 13 & 5 & 11 \\
\hline Buffalo (BF) & 15 & 15 & 7 & 17 \\
\hline
\end{tabular}

Management wants you to minimize the shipping costs while meeting demand. This problem involves the allocation of resources and can be modeled as a linear programming problem as we will discuss.

In engineering management the ability to optimize results in a constrained environment is crucial to success. Additionally, the ability to perform critical sensitivity analysis, or "what if analysis" is extremely important for decision making. Consider starting a new diet which needs to healthy. You go to a nutritionist that gives you lots of information on foods. They recommend sticking to six different foods: Bread, Milk, Cheese, Fish, Potato and Yogurt: and provides you a table of information including the average cost of the items: 


\begin{tabular}{rcccccc}
\hline & Bread & Milk & Cheese & Potato & Fish & Yogurt \\
\hline Cost, \$ & 2.0 & 3.5 & 8.0 & 1.5 & 11.0 & 1.0 \\
Protein, g & 4.0 & 8.0 & 7.0 & 1.3 & 8.0 & 9.2 \\
Fat, g & 1.0 & 5.0 & 9.0 & 0.1 & 7.0 & 1.0 \\
Carbohydrates, g & 15.0 & 11.7 & 0.4 & 22.6 & 0.0 & 17.0 \\
Calories, Cal & 90 & 120 & 106 & 97 & 130 & 180 \\
\hline
\end{tabular}

We go to a nutritionist and she recommends that our diet contains not less than 150 calories, not more than $10 \mathrm{~g}$ of protein, not less than $10 \mathrm{~g}$ of carbohydrates and not less than $8 \mathrm{~g}$ of fat. Also, we decide that our diet should have minimal cost. In addition we conclude that our diet should include at least $0.5 \mathrm{~g}$ of fish and not more than 1 cups of milk. Again this is an allocation of recourses problem where we want the optimal diet at minimum cost. We have six unknown variables that define weight of the food. There is a lower bound for Fish as $0.5 \mathrm{~g}$. There is an upper bound for Milk as $1 \mathrm{cup}$. To model and solve this problem, we can use linear programming.

Modern linear programming was the result of a research project undertaken by the US Department of Air Force under the title of Project SCOOP (Scientific Computation of Optimum Programs). As the number of fronts in the Second World War increased, it became more and more difficult to coordinate troop supplies effectively. Mathematicians looked for ways to use the new computers being developed to perform calculations quickly. One of the SCOOP team members, George Dantzig, developed the simplex algorithm for solving simultaneous linear programming problems. The simplex method has several advantageous properties: it is very efficient, allowing its use for solving problems with many variables; it uses methods from linear algebra, which are readily solvable.

In January 1952 the first successful solution to a linear programming (LP) problem was found using a high-speed electronic computer on the National Bureau of Standards SEAC machine. Today, most LP's are solved via high-speed computers. Computer specific software, such as LINDO, EXCEL SOLVER, GAMS, have been developed to help in the solving and analysis of LP problems. We will use the power of LINDO to solve our linear programming problems in this chapter.

To provide a framework for our discussions, we offer the following basic model:

Maximize (or minimize) $f(X)$

Subject to

$g_{i}(X) \mid \begin{aligned} & \geq \\ & = \\ & \leq\end{aligned} b_{i}$ for all $i$.

Now lets' explain this notation. The various component of the vector $X$ are called the decision variables of the model. These are the variables that can be controlled or manipulated. The 
function, $f(X)$, is called the objective function. By subject to, we connote that there are certain side conditions, resource requirement, or resource limitations that must be met. These conditions are called constraints. The constant $b_{i}$ represents the level that the associated constraint $g\left(X_{i}\right)$ and is called the right-hand side in the model.

Linear programming is a method for solving linear problems, which occur very frequently in almost every modern industry. In fact, areas using linear programming are as diverse as defense, health, transportation, manufacturing, advertising, and telecommunications. The reason for this is that in most situations, the classic economic problem exists - you want to maximize output, but you are competing for limited resources. The 'Linear' in Linear Programming means that in the case of production, the quantity produced is proportional to the resources used and also the revenue generated. The coefficients are constants and no products of variables are allowed.

In order to use this technique the company must identify a number of constraints that will limit the production or transportation of their goods; these may include factors such as labor hours, energy, and raw materials. Each constraint must be quantified in terms of one unit of output, as the problem solving method relies on the constraints being used.

An optimization problem that satisfies the following five properties is said to be a linear programming problem.

- There is a unique objective function, $f(X)$.

- Whenever a decision variable, $X$, appears in either the objective function or a constraint function, it must appear with an exponent of 1 , possibly multiplied by a constant.

- No terms contain products of decision variables.

- All coefficients of decision variables are constants.

- Decision variables are permitted to assume fractional as well as integer values.

Linear problems, by the nature of the many unknowns, are very hard to solve by human inspection, but methods have been developed to use the power of computers to do the hard work quickly. We will illustrate with two variables, graphically.

Supply Chain Management: A company owns railroad freight cars that can be sent all over the country. They need to work out what movements will be the most efficient in order to meet current customer needs and future needs on a probability basis, while minimizing time taken and costs incurred.

\section{Formulating linear programming problems}

A linear programming problem is a problem that requires an objective function to be maximized or minimized subject to resource constraints. The key to formulating a linear programming problem is recognizing the decision variables. The objective function and all constraints are written in terms of these decision variables. 
The conditions for a mathematical model to be a linear program (LP) were:

- all variables continuous (i.e. can take fractional values)

- a single objective (minimize or maximize)

- the objective and constraints are linear i.e. any term is either a constant or a constant multiplied by an unknown.

- The decision variables must be non-negative

LP's are important - this is because:

- many practical problems can be formulated as LP's

- there exists an algorithm (called the simplex algorithm) that enables us to solve LP's numerically relatively easily.

We will return later to the simplex algorithm for solving LP's but for the moment we will concentrate upon formulating LP's.

Some of the major application areas to which LP can be applied are:

- Blending

- Production planning

- Oil refinery management

- Distribution

- Financial and economic planning

- Manpower planning

- Blast furnace burdening

- Farm planning

We consider below some specific examples of the types of problem that can be formulated as LP's. Note here that the key to formulating LP's is practice. However a useful hint is that common objectives for LP's are minimize cost/maximize profit.

\section{Example 1 Manufacturing}

Consider the following problem statement:

A company wants to can two new different drinks for the holiday season. It takes 2 hours to can one gross of Drink A, and it takes 1 hour to label the cans. It takes 3 hours to can one gross of Drink B, and it takes 4 hours to label the cans. The company makes $\$ 10$ profit on one gross of Drink A and a $\$ 20$ profit of one gross of Drink B. Given that we have 20 hours to devote to canning the drinks and 15 hours to devote to labeling cans per week, how many cans of each type drink should the company package to maximize profits?

Required Submission for Formulation solution: 
Problem Identification: Maximize the profit of selling these new drinks.

Define variables:

$X_{1}=$ the number of gross cans produced for Drink A per week

$X_{2}=$ the number of gross cans produced for Drink B per week

Objective Function:

$Z=10 X_{1}+20 X_{2}$

1. Canning with only 20 hours available per week

$$
2 x_{1}+3 x_{2} \leq 20
$$

2. Labeling with only 15 hours available per week

$$
x_{1}+4 x_{2} \leq 15
$$

3. Non-negativity restrictions

$$
\begin{aligned}
& x_{1} \geq 0 \text { (non-negativity of the production items) } \\
& X_{2} \geq 0 \text { (non-negativity of the production items) }
\end{aligned}
$$

The Complete FORMULATION:

MAXIMIZE $Z=10 X_{1}+20 X_{2}$

subject to

$$
\begin{aligned}
& 2 x_{1}+3 x_{2} \leq 20 \\
& x_{1}+4 x_{2} \leq 15 \\
& x_{1} \geq 0 \\
& x_{2} \geq 0
\end{aligned}
$$

We will see in the next section how to solve these two-variable problems graphically.

\section{Example 2 Financial planning}

A bank makes four kinds of loans to its personal customers and these loans yield the following annual interest rates to the bank:

- First mortgage $14 \%$

- Second mortgage $20 \%$

- Home improvement $20 \%$

- Personal overdraft $10 \%$

The bank has a maximum foreseeable lending capability of $\$ 250$ million and is further constrained by the policies:

1. first mortgages must be at least $55 \%$ of all mortgages issued and at least $25 \%$ of all loans issued (in \$ terms)

2. second mortgages cannot exceed $25 \%$ of all loans issued (in \$ terms) 
3. to avoid public displeasure and the introduction of a new windfall tax the average interest rate on all loans must not exceed $15 \%$.

Formulate the bank's loan problem as an LP so as to maximize interest income while satisfying the policy limitations.

Note here that these policy conditions, while potentially limiting the profit that the bank can make, also limit its exposure to risk in a particular area. It is a fundamental principle of risk reduction that risk is reduced by spreading money (appropriately) across different areas.

\subsection{Financial planning formulation}

Note here that as in all formulation exercises we are translating a verbal description of the problem into an equivalent mathematical description.

A useful tip when formulating LP's is to express the variables, constraints and objective in words before attempting to express them in mathematics.

\subsection{Variables}

Essentially we are interested in the amount (in dollars) the bank has loaned to customers in each of the four different areas (not in the actual number of such loans). Hence let $x_{\mathrm{i}}=$ amount loaned in area $\mathrm{i}$ in a million of dollars (where $i=1$ corresponds to first mortgages, $i=2$ to second mortgages etc) and note that each $x_{\mathrm{i}}>=0(i=1,2,3,4)$.

Note here that it is conventional in LP's to have all variables $>=0$. Any variable $(X$, say $)$ which can be positive or negative can be written as $X_{1}-X_{2}$ (the difference of two new variables) where $X_{1}>=0$ and $X_{2}>=0$.

\subsection{Constraints}

a. limit on amount lent

$x_{1}+x_{2}+x_{3}+x_{4} \leq 250$

b. policy condition 1

$x_{1} \geq 0.55\left(x_{1}+x_{2}\right)$

i.e. first mortgages $>=0.55$ (total mortgage lending) and also

$x_{1} \geq 0.25\left(x_{1}+x_{2}+x_{3}+x_{4}\right)$

i.e. first mortgages $\geq 0.25$ (total loans)

c. policy condition 2

$x_{2} \leq 0.25\left(x_{1}+x_{2}+x_{3}+x_{4}\right)$ Inline formula 
d. policy condition 3 - we know that the total annual interest is $0.14 x_{1}+0.20 x_{2}+0.20 x_{3}+$ $0.10 x_{4}$ on total loans of $\left(x_{1}+x_{2}+x_{3}+x_{4}\right)$. Hence the constraint relating to policy condition (3) is

$$
0.14 x_{1}+0.20 x_{2}+0.20 x_{3}+0.10 x_{4} \leq 0.15\left(x_{1}+x_{2}+x_{3}+x_{4}\right)
$$

\subsection{Objective function}

To maximize interest income (which is given above) i.e.

Maximize $Z=0.14 x_{1}+0.20 x_{2}+0.20 x_{3}+0.10 x_{4}$

Example 3 Blending and Formulation

Consider the example of a manufacturer of animal feed who is producing feed mix for dairy cattle. In our simple example the feed mix contains two active ingredients. One kg of feed mix must contain a minimum quantity of each of four nutrients as below:

\begin{tabular}{ccccc}
\hline Nutrient & $A$ & $B$ & $C$ & $D$ \\
gram & 90 & 50 & 20 & 2 \\
\hline
\end{tabular}

The ingredients have the following nutrient values and cost

\begin{tabular}{lccccc}
\hline & $A$ & $B$ & $C$ & $D$ & Cost/kg \\
Ingredient 1 (gram/kg) & 100 & 80 & 40 & 10 & 40 \\
Ingredient 2 (gram/kg) & 200 & 150 & 20 & 0 & 60 \\
\hline
\end{tabular}

What should be the amounts of active ingredients in one $\mathrm{kg}$ of feed mix that minimizes cost?

\subsection{Blending problem solution}

\section{Variables}

In order to solve this problem it is best to think in terms of one kilogram of feed mix. That kilogram is made up of two parts - ingredient 1 and ingredient 2:

$x_{1}=$ amount $(\mathrm{kg})$ of ingredient 1 in one $\mathrm{kg}$ of feed mix

$x_{2}=$ amount $(\mathrm{kg})$ of ingredient 2 in one $\mathrm{kg}$ of feed mix

where $\mathrm{x}_{1} \geq 0, \mathrm{x}_{2} \geq 0$

Essentially these variables $\left(\mathrm{x}_{1}\right.$ and $\left.\mathrm{x}_{2}\right)$ can be thought of as the recipe telling us how to make up one kilogram of feed mix.

\section{Constraints}

- nutrient constraints 
$100 \mathrm{x}_{1}+200 \mathrm{x}_{2}>=90$ (nutrient A)

$80 \mathrm{x}_{1}+150 \mathrm{x}_{2}>=50$ (nutrient B)

$40 \mathrm{x}_{1}+20 \mathrm{x}_{2}>=20$ (nutrient $\mathrm{C}$ )

$10 \mathrm{x}_{1}>=2$ (nutrient D)

- balancing constraint (an implicit constraint due to the definition of the variables)

$x_{1}+x_{2}=1$

\section{Objective function}

Presumably to minimize cost, i.e.

Minimize $\mathrm{Z}=40 \mathrm{x}_{1}+60 \mathrm{x}_{2}$

This gives us our complete LP model for the blending problem.

Example 4 Production planning problem

A company manufactures four variants of the same table and in the final part of the manufacturing process there are assembly, polishing and packing operations. For each variant the time required for these operations is shown below (in minutes) as is the profit per unit sold.

\begin{tabular}{ccccc}
\hline Variant 1 & Assembly & Polish & Pack & Profit (\$) \\
& 2 & 3 & 2 & 1.50 \\
2 & 4 & 2 & 3 & 2.50 \\
3 & 3 & 3 & 2 & 3.00 \\
4 & 7 & 4 & 5 & 4.50 \\
\hline
\end{tabular}

Given the current state of the labor force the company estimate that, each year, they have 100,000 minutes of assembly time, 50,000 minutes of polishing time and 60,000 minutes of packing time available. How many of each variant should the company make per year and what is the associated profit?

\section{Variables}

Let:

$x_{\mathrm{i}}$ be the number of units of variant $i(i=1,2,3,4)$ made per year, where $x_{\mathrm{i}} \geq 0 i=1,2,3,4$

\section{Constraints}

Resources for the operations of assembly, polishing, and packing

$2 \mathrm{x}_{1}+4 \mathrm{x}_{2}+3 \mathrm{x}_{3}+7 \mathrm{x}_{4}<=100,000$ (assembly)

$3 x_{1}+2 x_{2}+3 x_{3}+4 x_{4}<=50,000$ (polishing)

$2 x_{1}+3 x_{2}+2 x_{3}+5 x_{4}<=60,000$ (packing)

Objective function 
Maximize $Z=1.5 x_{1}+2.5 x_{2}+3.0 x_{3}+4.5 x_{4}$

\section{Example 5 Shipping}

Consider planning the shipment of needed items from the warehouses where they are manufactured and stored to the distribution centers where they are needed as shown in the introduction. There are three warehouses at different cities: Detroit, Pittsburgh and Buffalo. They have 250, 130 and 235 tons of paper accordingly. There are four publishers in Boston, New York, Chicago and Indianapolis. They ordered 75, 230, 240 and 70 tons of paper to publish new books.

There are the following costs in dollars of transportation of one ton of paper:

\begin{tabular}{ccccc}
\hline From \ To & Boston (BS) & New York (NY) & Chicago (CH) & Indianapolis (IN) \\
Detroit (DT) & 15 & 20 & 16 & 21 \\
Pittsburgh (PT) & 25 & 13 & 5 & 11 \\
Buffalo (BF) & 15 & 15 & 7 & 17 \\
\hline
\end{tabular}

Management wants you to minimize the shipping costs while meeting demand.

We define $x_{\mathrm{ij}}$ to be the travel from city $i$ ( 1 is Detroit, 2 is Pittsburg, 3 is Buffalo) to city $j$ ( 1 is Boston, 2 is New York, 3 is Chicago, and 4 is Indianapolis).

Minimize $Z=15 x_{11}+20 x_{12}+16 x_{13}+21 x_{14}+25 x_{21}+13 x_{22}+5 x_{23}+11 x_{24}+15 x_{31}+15 x_{32}+7 x_{33}+17 x_{34}$

Subject to:

$\mathrm{x}_{11}+\mathrm{x}_{12}+\mathrm{x}_{13}+\mathrm{x}_{14} \leq 250$ (availability in Detroit)

$\mathrm{x}_{21}+\mathrm{x}_{22}+\mathrm{x}_{23}+\mathrm{x}_{24} \leq 130$ (availability in Pittsburg)

$\mathrm{x}_{31}+\mathrm{x}_{32}+\mathrm{x}_{33}+\mathrm{x}_{34} \leq 235$ (availability in Buffalo)

$\mathrm{x}_{11}+\mathrm{x}_{21}+\mathrm{x}_{31} \geq 75$ (demand Boston)

$x_{12}+x_{22}+x_{32} \geq 230$ (demand New York)

$x_{13}+x_{23}+x_{334} \geq 240$ (demand Chicago)

$\mathrm{x}_{14}+\mathrm{x}_{24}+\mathrm{x}_{34} \geq 70$ (demand Indianapolis)

$\mathrm{x}_{\mathrm{ij}} \geq 0$

\section{LP geometry}

Many applications in business and economics involve a process called optimization. In optimization problems, you are asked to find the minimum or the maximum result. This section illustrates the strategy in graphical simplex of linear programming. We will restrict ourselves in this graphical context to two-dimensions. Variables in the simplex method are restricted to positive variables (for example $x \geq 0$ ). 
A two-dimensional linear programming problem consists of a linear objective function and a system of linear inequalities called constraints. The objective function gives the linear quantity that is to be maximized (or minimized). The constraints determine the set of feasible solutions.

\section{Memory chips for CPUs}

Let's start with a manufacturing example. Suppose a small business wants to know how many of two types of high-speed computer chips to manufacturer weekly to maximize their profits. First, we need to define our decision variables. Let,

$x_{1}=$ number of high speed chip type A to produce weekly

$x_{2}=$ number of high speed chip type B to produce week

The company reports a profit of $\$ 140$ for each type A chip and $\$ 120$ for each type B chip sold. The production line reports the following information:

\begin{tabular}{rccc}
\hline & Chip A & Chip B & Quantity available \\
Assembly time (hours) & 2 & 4 & 1400 \\
Installation time (hours) & 4 & 3 & 1500 \\
Profit ( per unit) & 140 & 120 & \\
\hline
\end{tabular}

The constraint information from the table becomes inequalities that are written mathematical as:

$2 \mathrm{x}_{1}+4 \mathrm{x}_{2} \leq 1400$ (assembly time)

$4 \mathrm{x}_{1}+3 \mathrm{x}_{2} \leq 1500$ (installation time)

$x_{1} \geq 0, x_{2} \geq 0$

The profit equation is:

Profit $=140 \mathrm{x}_{1}+120 \mathrm{x}_{2}$

\section{The feasible region}

The constraints of a linear program, which include any bounds on the decision variables, essentially shape the region in the $x-y$ plane that will be the domain for the objective function prior to any optimization being performed. Every inequality constraint that is part of the formulation divides the entire space defined by the decision variables into 2 parts: the portion of the space containing points that violate the constraint, and the portion of the space containing points that satisfy the constraint.

It is very easy to determine which portion will contribute to shaping the domain. We can simply substitute the value of some point in either half-space into the constraint. Any point will do, but the origin is particularly appealing. Since there's only one origin, if it satisfies the constraint, then the half-space containing the origin will contribute to the domain of the objective function.

When we do this for each of the constraints in the problem, the result is an area representing the intersection of all the half-spaces that satisfied the constraints individually. This intersection 
is the domain for the objective function for the optimization. Because it contains points that satisfy all the constraints simultaneously, these points are considered feasible to the problem. Naturally, the common name for this domain is the feasible region.

Consider our constraints:

$2 \mathrm{x}_{1}+4 \mathrm{x}_{2} \leq 1400$ (assembly time)

$4 x_{1}+3 x_{2} \leq 1500$ (installation time)

$x_{1} \geq 0, x_{2} \geq 0$

For our graphical work we use the constraints: $x_{1} \geq 0, x_{2} \geq 0$ to set the region. Here, we are strictly in the $x_{1}-x_{2}$ plane (the first quadrant).

Let's first take constraint \#1 (assembly time) in the first quadrant: $2 x_{1}+4 x_{2} \leq 1400$

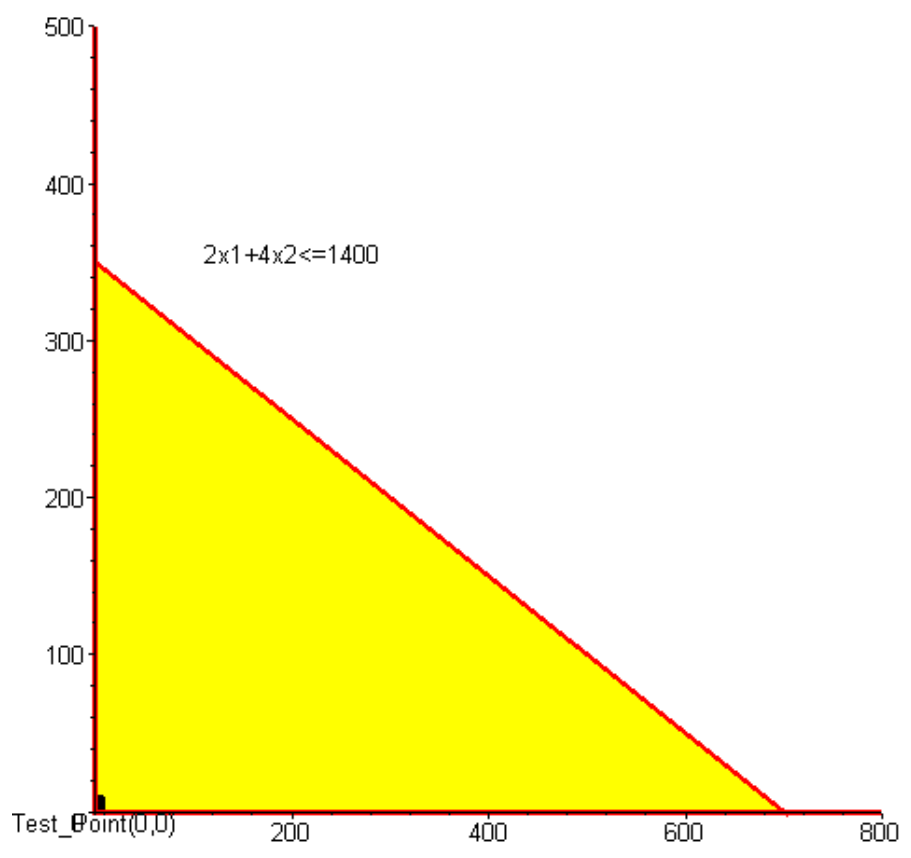

Figure 1. Shaded Inequality

We see the shaded region for constraint 1 that makes the inequality true. We repeat this process for all constraints to obtain Figure 2. 


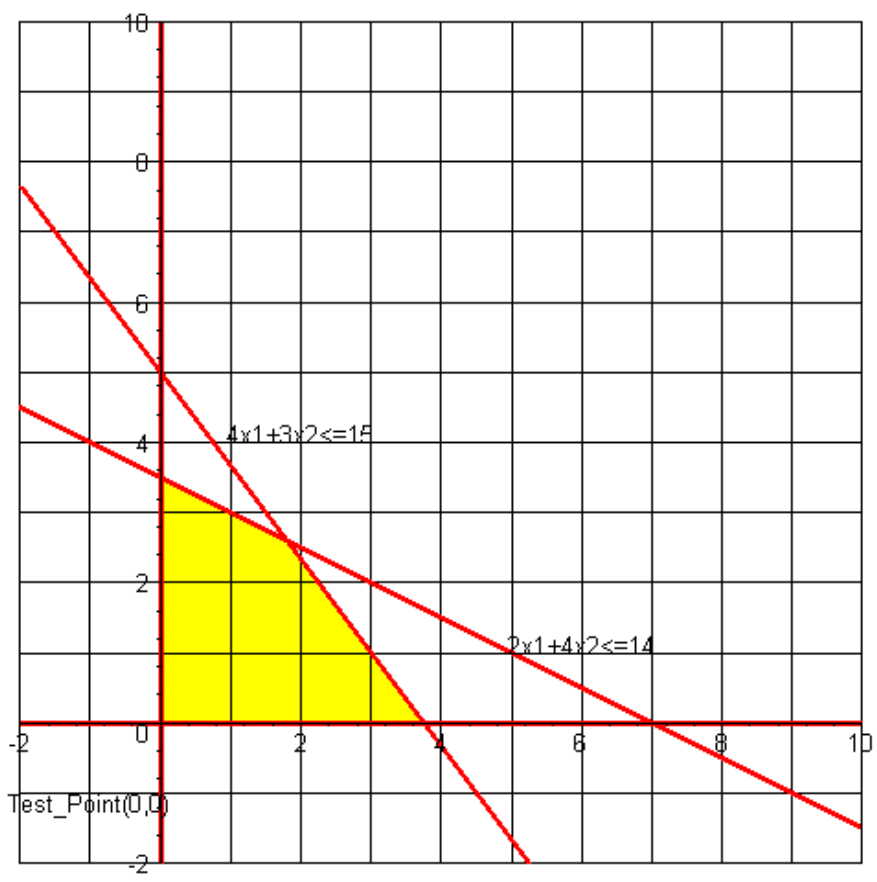

Figure 2. Plot of (1) the assembly hour's constraint and (2) the installation hour's constraint in the first quadrant

Figure 2 shows a plot of (1) the assembly hour's constraint and (2) the installation hour's constraint in the first quadrant. Along with the non-negativity restrictions on the decision variables, the intersection of the half-spaces defined by these constraints is the feasible region shown in yellow. This area represents the domain for the objective function optimization.

\section{Finding the feasible region}

Shade in the feasible region defined by the following set of constraints:

$x+2 y \leq 20$

$2 \mathrm{x}+\mathrm{y} \leq 20$

$x \geq 0, y \geq 0$

The feasible region is the set of ordered pairs $(x, y)$ that satisfy all four constraints simultaneously. They are points that lie below $x+2 y \leq 20$, below $2 x+y \leq 20$, and above $y=0$ and to the right of $x=0$. We note that the non-negativity constraints, $x \geq 0, y \geq 0$, restrict the feasible region to the first quadrant. $\leq$

If the problem is well behaved, this should be a closed and bounded polyhedral shape, called a polyhedron, such as the one shown in yellow. It does not have to be so. Sometimes the orientation and location of the constraints fail to hold back the objective function in the direction of the optimization. When this happens, the problem is unbounded; the objective 


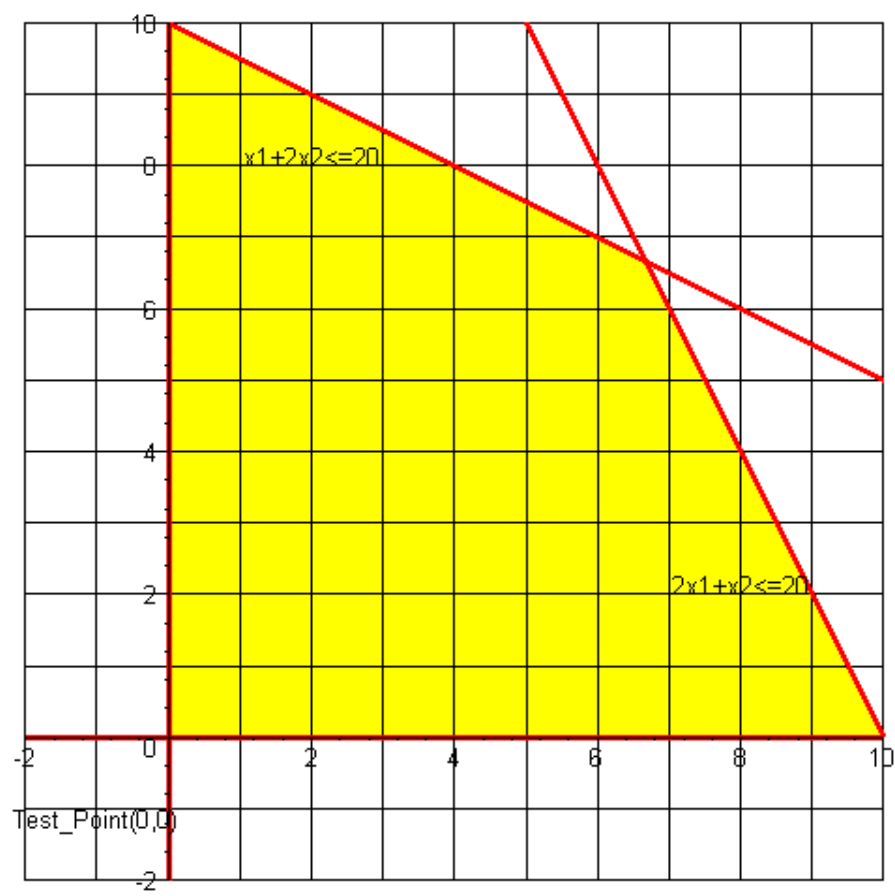

Figure 3. Shaded Feasible Region

function value goes off to positive or negative infinity. Can you draw a sketch of a situation in which this will happen?

Other times, the intersection of the half-spaces is an empty set. In this case, the problem is infeasible; there are no possible solutions that will satisfy the requirements of all the constraints simultaneously. Can you draw a sketch of a situation in which this will happen?

\subsection{Solving a linear programming problem graphically}

Recall that we have decision variables defined and an objection function that is to be maximized or minimized. Although all points inside the feasible region provide feasible solutions the solution, if one exists, occurs according to the Fundamental Theorem of Linear Programming:

If the optimal solution exists, then it occurs at a corner point of the feasible region.

Notice the various corners formed by the intersections of the constraints in example. These points are of great importance to us. There is a cool theorem (didn't know there were any of these, huh?) in linear optimization that states, "if an optimal solution exists, then an optimal corner point exists." The result of this is that any algorithm searching for the optimal solution to a linear program should have some mechanism of heading toward the corner point where the solution will occur. If the search procedure stays on the outside border of the feasible region 
while pursuing the optimal solution, it is called an exterior point method. If the search procedure cuts through the inside of the feasible region, it is called an interior point method.

Thus, in a linear programming problem, if there exists a solution, it must occur at a corner point of the set of feasible solutions (these are the vertices of the region). Note that in Figure 3 the corner points of the feasible region are the coordinates: $(0,0),(0,10)(10,0)$, and $(20 / 3,20 / 3)$.

How did we get the point $(20 / 3,20 / 3)$ ?

This point is the intersection of the lines: $x+2 y=20$ and $2 x+y=20$. You have solved these problems before. In the second constraint, let $y=20-2 x$ and substitute (20-2x) for $y$ in the first equation, so $x+2(20-2 x)=20$ and solve for $x$. We find $3 x=20$ or $x=20 / 3$. Since $y=20-2 x$, we substitute $x=20 / 3$ for $\mathrm{x}$ and solve for $\mathrm{y}$. Now, $y=20 / 3$.

Now, that we have all the possible solution coordinates for $(x, y)$, we need to know which is the optimal solution. Here is how we determine that:

We evaluate the objective function at each point and choose the best solution.

Assume our objective function is to Maximize $Z=2 x+2 y$. We can set up a table of coordinates and corresponding Z-values as follows.

\begin{tabular}{cc}
\hline Coordinate of Corner Point & $Z=2 x+2 y$ \\
\hline$(0,0)$ & $Z=0$ \\
\hline$(0,10)$ & $Z=(2)(20 / 3)+(2)(20 / 3)=80 / 3 *$ \\
\hline$(20 / 3,20 / 3)$ & $Z=(2)(10)+(2)(0)=20$ \\
\hline$(10,0)$ & $Z=80 / 3=26.666$ \\
\hline Best solution is $(20 / 3,20 / 3)$ & \\
\hline
\end{tabular}

Graphically, we see the result by plotting the objective function line, $Z=2 x+2 y$, with the feasible region. Determine the parallel direction for the line to maximize (in this case) $Z$. Move the line parallel until it crosses the last point in the feasible set. That point is the solution. The line that goes through the origin at a slope of $-2 / 2$ is called the ISO-Profit line. We have provided this Figure 4 below:

Here are the steps for solving a linear programming problem involving only two variables. 


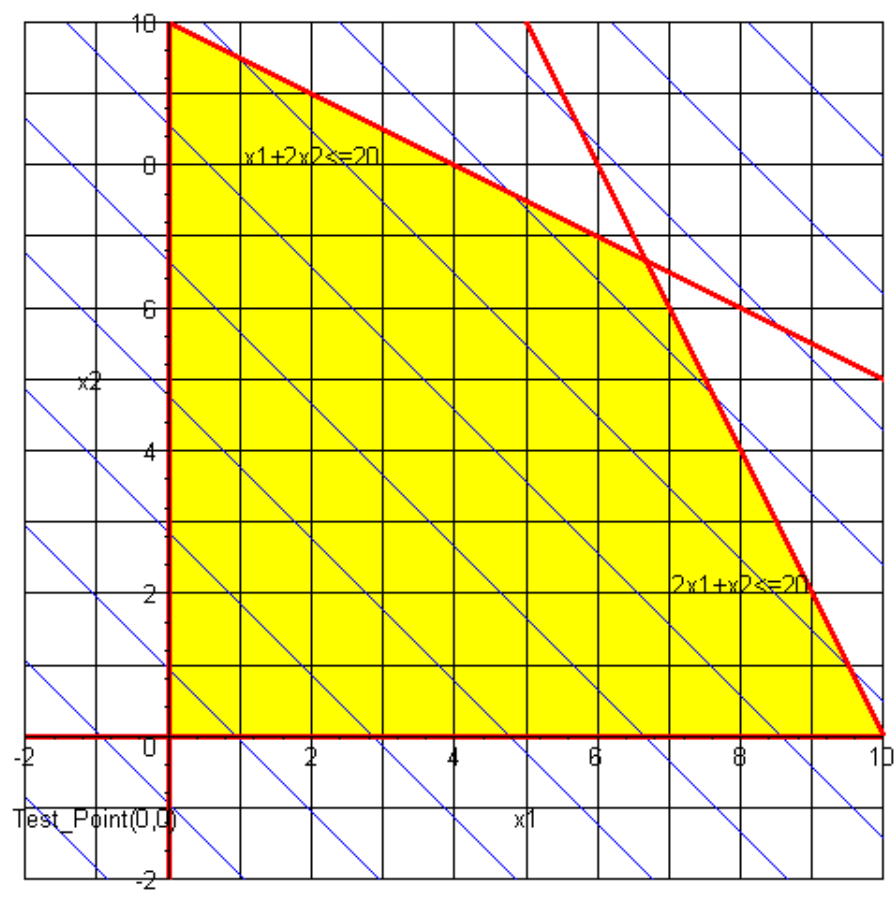

Figure 4. Iso-Profit Lines Added

1. Sketch the region corresponding to the system of constraints. The points satisfying all constraints make up the feasible solution.

2. Find all the corner points (or intersection points in the feasible region).

3. Test the objective function at each corner point and select the values of the variables that optimize the objective function. For bounded regions, both a maximum and a minimum will exist. For an unbounded region, if a solution exists, it will exist at a corner.

\subsection{Minimization problem}

Minimize $Z=5 x+7 y$

Subject to:

$2 x+3 y \geq 6$

$3 x-y \leq 15$

$-x+y \leq 4$

$2 x+5 y \leq 27$

$x \geq 0$

$y \geq 0$ 


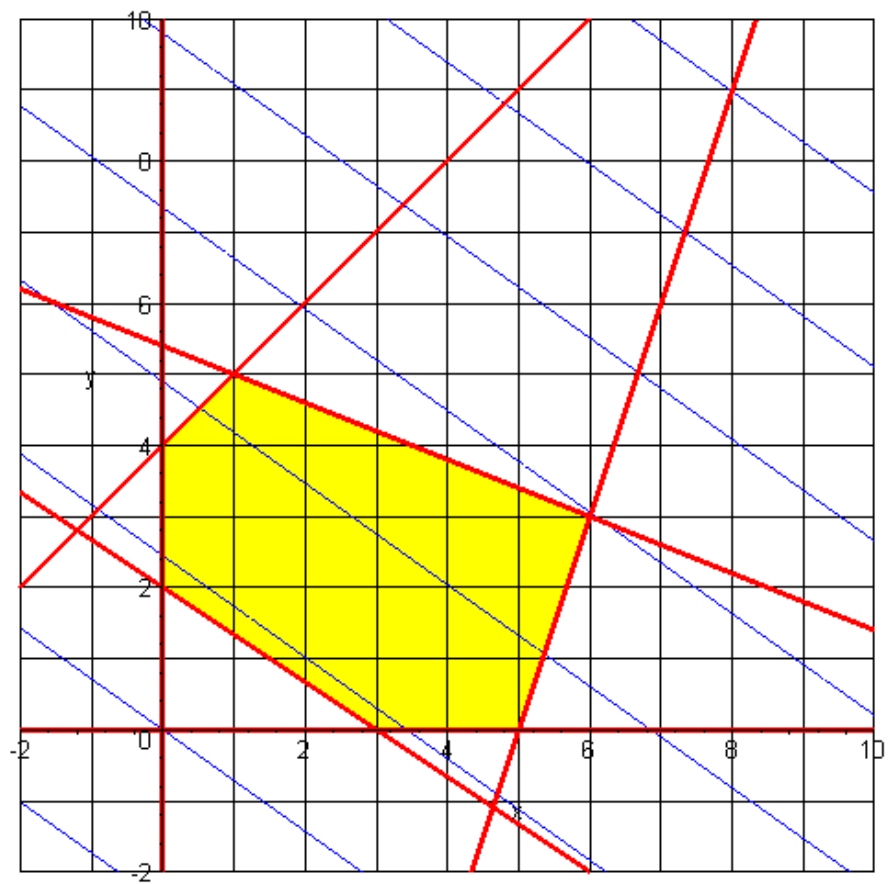

The corner points in Figure 5 are $(0,2),(0,4))(1,5),(6,3),(5,0)$, and $(3,0)$. See if you can find all these corner points.

If we evaluate $Z=5 x+7 y$ at each of these points, we find:

\begin{tabular}{cc}
\hline Corner Point & $Z=5 x+7 y$ (MINIMIZE) \\
\hline$(0,2)$ & $Z=14$ \\
\hline$(1,5)$ & $Z=40$ \\
\hline$(6,3)$ & $Z=51$ \\
\hline$(5,0)$ & $Z=25$ \\
\hline$(3,0)$ & $Z=15$ \\
\hline$(0,4)$ & $Z=28$ \\
\hline
\end{tabular}

The minimum value occurs at $(0,2)$ with a $Z$ value of 14 . Notice in our graph that the blue ISOProfit line will last cross the point $(0,2)$ as it move out of the feasible region in the direction that Minimizes $Z$. 


\subsection{Unbounded case}

Let's examine the concept of an unbounded feasible region. Look at the constraints:

$x+2 y \geq 4$

$3 x+y \geq 7$

$x \geq 0$ and $y \geq 0$

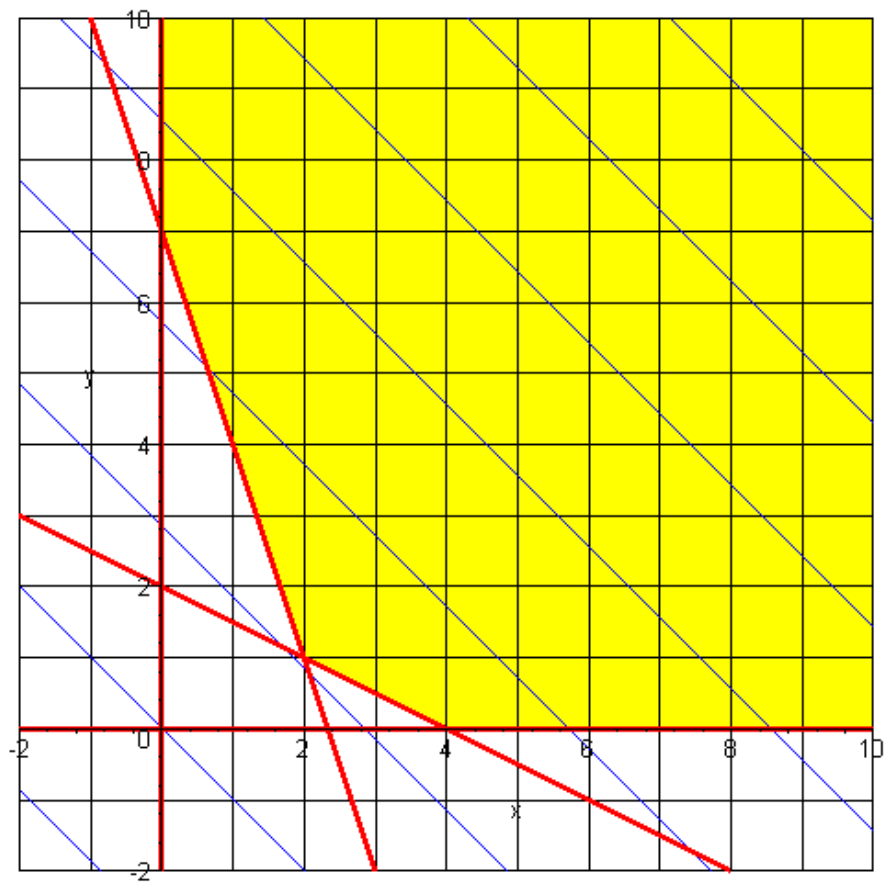

Note that the corner points are $(0,7),(2,1)$ and $(4,0)$ and the region is unbounded. If our solution is to Minimize $Z=x+y$ then our solution is: $(2,1)$ with $Z=3$. Determine why there is no solution to the LP to Maximize $Z=x+y$.

\section{Graphical sensitivity analysis}

One of the most important topics in linear programming is sensitivity analysis. In this section we illustrate the concept of sensitivity analysis through a graphical example. Sensitivity analysis is concerned with how changes in the parameters (coefficient and right-hand-side values) affect the LP's optimal solution. Very often, we can ascertain whether the optimal solution variables remain the same (perhaps with different solution values) or whether the variables will change. 
Reconsider the following example:

Maximize $2 x+2 y$

Subject to:

$\mathrm{x}+2 \mathrm{y} \leq 20$

$2 \mathrm{x}+\mathrm{y} \leq 20$

$x \geq 0, y \geq 0$

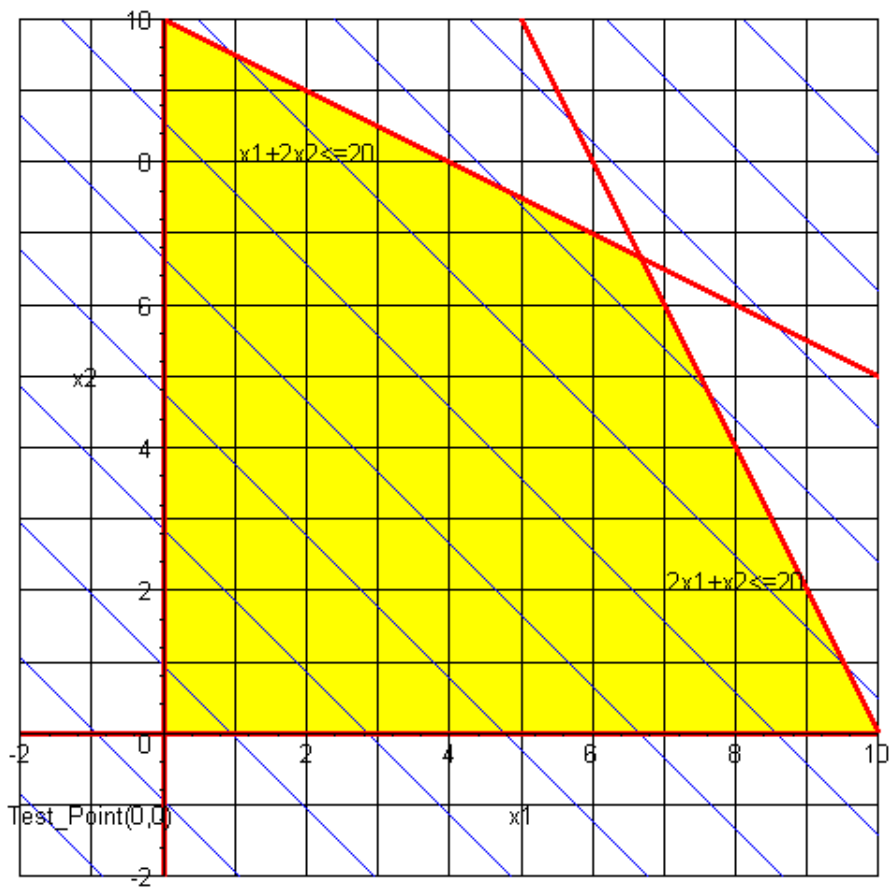

The corners of the feasible region with the respective objective function values are shown in the following table:

\begin{tabular}{lll}
\hline Point & Coordinates & Z-Value \\
\hline A & $(0,0)$ & $Z=0$ \\
\hline B & $(10,0)$ & $Z=20$ \\
\hline C & $(0,10)$ & $Z=20$ \\
\hline$D$ & $(20 / 3,20 / 3)$ & $Z=80 / 3=26.66666$ Optimal \\
\hline
\end{tabular}

The optimal solution is currently $x=20 / 3, y=20 / 3$ and $Z=80 / 3$. 


\subsection{Graphical analysis of the effect of an objective function coefficient}

Recall our objective function:

$\mathrm{Z}=2 \mathrm{x}+2 \mathrm{y}$

The slope of this objective function line is -1 . The solution is currently at Point $\mathrm{D}$, the coordinates $(20 / 3,20 / 3)$. Recall that the optimal solution, if it exists, must lie at the corner point of the feasible region. The next closest points to D are B and C. B lies on constraint (2) and C lies on constraints (1). The slope of constraint (1) is $-1 / 2$ and the slope of constraint (2) is -2 .

You can see that if we change the coefficients, let say, A $x+2 y$, its slope is $-\mathrm{A} / 2$. Currently, $\mathrm{A}$ is 2 with a slope of -1 . The bounds for the slope to retain Point $D$ as a solution is between -2 $\leq$ slope $\leq-1 / 2$ (Note at equality we will have alternate optimal solutions). We can easily solve for the values of $A$ that keep the slope within its bounds. $1 \leq A \leq 4$. Since A is currently 2 , it can decrease by 1 unit or increase by 2 units and still keep Point D optimal.

Let's try $2 x+$ by with its slope $-2 / b$. Currently, B is 2 with a slope of -1 . The bounds for the slope to retain Point $D$ as a solution is between $-2 \leq$ slope $\leq-1 / 2$ (Note at equality we will have alternate optimal solutions). We can easily solve for the values of $B$ that keep the slope within its bounds. $1 \leq \mathrm{B} \leq 4$. Since B is currently 2 , it can decrease by 1 unit or increase by 2 units and still keep Point D optimal.

\subsection{Graphical analysis of the effect of a change in a right-hand side coefficient}

The right-hand side value for each constraint controls the y-intercept of the problem. The slopes will remain the same. Changing the right-hand side yields a parallel line to the original constraint. Point D is the intersection of constraints (1) and (2). Points B and C are the intersections of constraints (1) and Constraint (2) each with non-negativity.

Let's consider constraint (1), $x+2 y \leq \mathrm{B}$

The value of $B$ is currently 20. If it is reduced then the line moves down until it intersects point $(10,0)$. Using $(10,0)$ in the equation yields a $B$ value of 10 . If we increase $B$, then we move up to an original infeasible point $(0,20)$, which will now become feasible. Using $(0,20)$ in the equation yields a $B$ value of 40 .

Thus, $10 \leq \mathrm{B} \leq 40$. This is a decrease of 10 units and an increase of 20 units.

Let's consider constraint (2), $2 x+y \leq \mathrm{C}$

The value of $C$ is currently 20. If it is reduced then the line moves down until it intersects point $(0,10)$. Using $(0,10)$ in the equation yields a $C$ value of 10 . If we increase $C$, then we move up to an original infeasible point $(20,0)$, which will now become feasible. Using $(20,0)$ in the equation yields a $C$ value of 40 .

Thus, $10 \leq C \leq 40$. This is a decrease of 10 units and an increase of 20 units.

Maximize $\mathrm{Z}=20 \mathrm{x}_{1}+30 \mathrm{x}_{2}$

Subject to: 


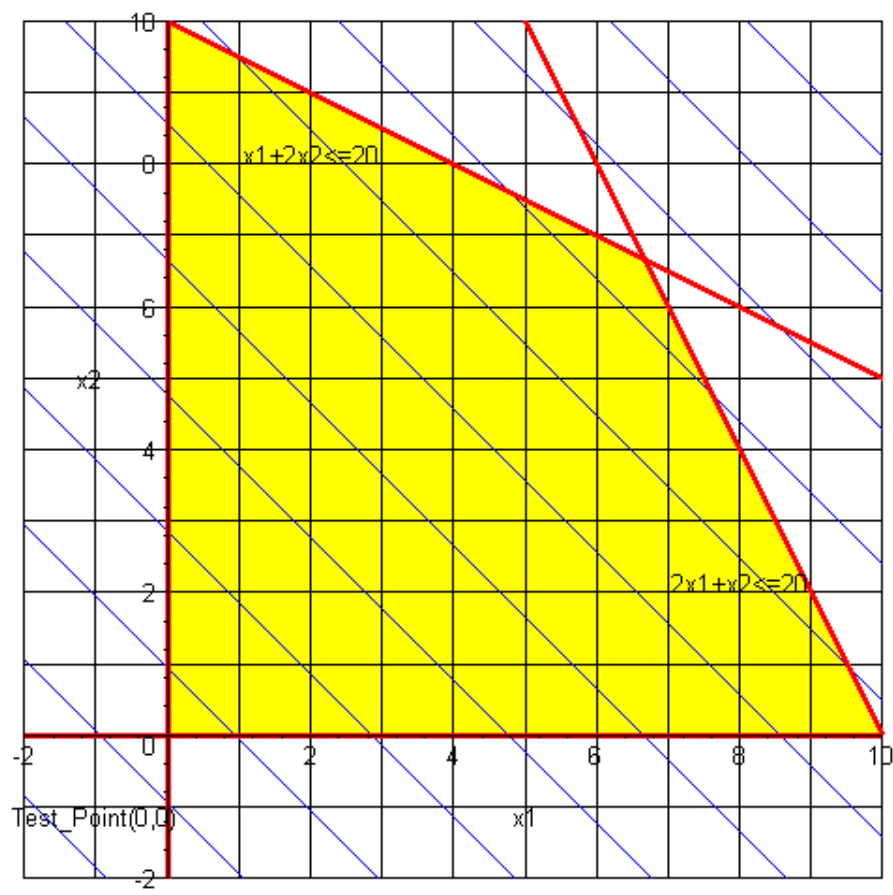

$2 \mathrm{x}_{1}+4 \mathrm{x}_{3} \leq 1400$ (assembly time)

$4 x_{1}+3 x_{3} \leq 1500$ (installation time)

The solution is $(180,260), Z=11400$.

Let's see the effects of changing the coefficients of the objective function since management has some leeway with the revenues and costs

$\mathrm{Z}=20 \mathrm{x}_{1}+30 \mathrm{x}_{2}$

The slope of this objective function line is $-2 / 3$. The solution is currently at Point $D$, the coordinates $(180,260)$. Recall that the optimal solution, if it exists, must lie at the corner point of the feasible region. The next closest points to D are B and C. B lies on constraint (2) and C lies on constraints (1). The slope of constraint (1) is $-1 / 2$ and the slope of constraint (2) is $-4 / 3$.

You can see that if we change the coefficients, let say, A $x_{1}+30 x_{2}$, its slope is $-\mathrm{A} / 30$. Currently, $A$ is 20 with a slope of $-2 / 3$. The bounds for the slope to retain Point $D$ has a solution between $-4 / 3 \leq$ slope $\leq-1 / 2$. We can easily solve for the values of $A$ that keep the slope within its bounds. $15 \leq \mathrm{A} \leq 40$. Since $\mathrm{A}$ is currently 20 , it can decrease by 5 units or increase by 20 units and still keep Point D optimal.

Now, let's try changing the coefficient of the other variable: $20 x+B y$ with its slope $-20 / B$. Currently, B is 30 with a slope of $-2 / 3$. The bounds for the slope to retain Point $\mathrm{D}$ as a solution is between $-4 / 3 \leq$ slope $\leq-1 / 2$ We can easily solve for the values of $B$ that keep the slope within 


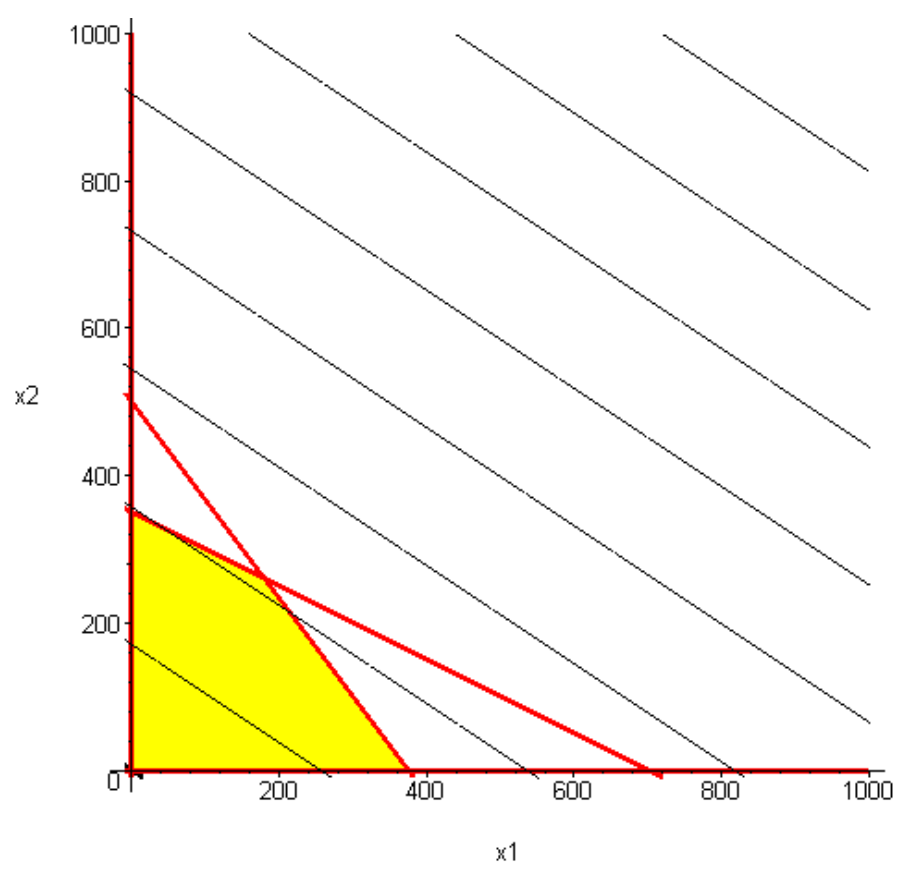

its bounds. $15 \leq B \leq 40$. Since B is currently 30 , it can decrease by 15 units or increase by 10 units and still keep Point D optimal.

\section{The simplex method}

In the previous sections we discussed formulating linear programming problems, solving twodimensional linear programming problems by graphical methods, and graphical sensitivity analysis. The graphical method illustrates some key concepts, but is only practical for problems with two variables. As you see linear programming problems often have more than two variables. With problems with more than two variables, an algebraic method may be used. This method is called the Simplex Method. The Simplex Method, developed by George Dantzig in 1947 incorporates both optimality and feasibility tests to find the optimal solution(s) to a linear program (if one exists).

An optimality test shows whether or not an intersection point corresponds to a value of the objective function better than the best value found so far.

A feasibility test determines whether the proposed intersection point is feasible. It does not violate any of the constraints. 
The simplex method starts with the selection of a corner point (usually the origin if it is a feasible point) and then, in a systematic method, moves to adjacent corner points of the feasible region until the optimal solution is found or it can be shown that no solution exists.

\subsection{Steps of the simplex method}

1. Tableau Format: Place the linear program in Tableau Format, as explained below.

Maximize $Z=25 x_{1}+30 x_{2}$

Subject to:

$20 \mathrm{x}_{1}+30 \mathrm{x}_{2} \leq 6905$

$\mathrm{x}_{1}+4 \mathrm{x}_{2} \leq 120$

$\mathrm{x}_{1}, \mathrm{x}_{2}, \geq 0$

To begin the simplex method, we start by converting the inequality constraints (of the form $<$ ) to equality constraints. This is accomplished by adding a unique, non-negative variable, called a slack variable, to each constraint. For example the inequality constraint $20 x_{1}+30 x_{2} \leq 690$ is converted to an equality constraint by adding the slack variable $S_{1}$ to obtain:

$20 \mathrm{x}_{1}+30 \mathrm{x}_{2}+\mathrm{S}_{1}=690$, where $\mathrm{S}_{1} \geq 0$.

The inequality $20 x_{1}+30 x_{2} \leq 690$ states that the sum $20 x_{1}+30 x_{2}$ is less than or equal to 690 . The slack variable "takes up the slack" between the values used for $x_{1}$ and $x_{2}$ and the value 690 . For example, if $x_{1}=x_{2}=0$, the $S_{1}=690$. If $x_{1}=24, x_{2}=0$ then $20(24)+30(0)+S_{1}=690$, so $S_{1}=210$.

A unique slack variable must be added to each inequality constraint.

Maximize $\mathrm{Z}=25 \mathrm{x}_{1}+30 \mathrm{x}_{2}$

Subject to:

$20 \mathrm{x}_{1}+30 \mathrm{x}_{2}+\mathrm{S}_{1}=690$

$5 \mathrm{x}_{1}+4 \mathrm{x}_{2}+\mathrm{S}_{2}=120$

$\mathrm{x}_{1} \geq 0, \mathrm{x}_{2} \geq 0, \mathrm{~S}_{1} \geq 0, \mathrm{~S}_{2} \geq 0$

Adding slack variables makes the constraint set a system of linear equations. We write these with all variables on the left side of the equation and all constants on the right hand side.

We will even rewrite the objective function by moving all variables to the left-hand side.

Maximize $Z=25 x_{1}+30 x_{2}$ is written as

Z- $25 \mathrm{x}_{1}-30 \mathrm{x}_{2}=0$

Now, these can be written in the following form:

$$
\begin{gathered}
Z-25 x_{1}-30 x_{2}=0 \\
20 x_{1}+30 x_{2}+S_{1}=690 \\
5 x_{1}+4 x_{2}+S_{2}=120
\end{gathered}
$$


or more simply in a matrix. This matrix is called the simplex tableau.

\begin{tabular}{lllllll}
\hline$Z$ & $x_{1}$ & $x_{2}$ & $S_{1}$ & $S_{2}$ & RHS \\
\hline 1 & -25 & -30 & 0 & 0 & $=$ & 0 \\
\hline 0 & 20 & 30 & 1 & 0 & $=$ & 690 \\
\hline 0 & 5 & 4 & 0 & 1 & $=$ & 120 \\
\hline
\end{tabular}

2. Initial Extreme Point: The Simplex Method begins with a known extreme point, usually the origin $(0,0)$ for many of our examples. The requirement for a basic feasible solution gives rises to special Simplex methods such as Big M and Two-Phase Simplex, which can be studied in a linear programming course.

The Tableau previously shown contains the corner point $(0,0)$ is our initial solution.

\begin{tabular}{lllllll}
\hline$Z$ & $x_{1}$ & $x_{2}$ & $S_{1}$ & $S_{2}$ & RHS \\
\hline 1 & -25 & -30 & 0 & 0 & $=$ & 0 \\
\hline 0 & 20 & 30 & 1 & 0 & $=$ & 690 \\
\hline 0 & 5 & 4 & 0 & 1 & $=$ & 120 \\
\hline
\end{tabular}

We read this solution as follows:

$\mathrm{x}_{1}=0$

$\mathrm{x}_{2}=0$

$\mathrm{S}_{1}=690$

$\mathrm{S}_{2}=120$

$\mathrm{Z}=0$

Let's continue to define a few of these variables further. We have 5 variables $\left\{Z, x_{1}, x_{2}, S_{1}, S_{2}\right\}$ and 3 equations. We can have at most 3 solutions. $Z$ will always be a solution by convention of our tableau. We have two non-zero variables among $\left\{x_{1}, x_{2}, S_{1}, S_{2}\right\}$. These non-zero variables are called the basic variables. The remaining variables are called the non-basic variables. The corresponding solutions are called the basic feasible solutions (FBS) and correspond to corner points. The complete step of the simplex method produces a solution that corresponds to a corner point of the feasible region. These solutions are read directly from the tableau matrix.

We also note the basic variables are variables that have a column consisting of one 1 and the rest zeros in their column. We will add a column to label these as shown below:

\begin{tabular}{lllllll}
\hline \multicolumn{3}{l}{$\begin{array}{l}\text { Basic } \\
\text { Variable }\end{array}$} & & \multicolumn{3}{l}{ Basic variable Basic variable } \\
\hline $\mathrm{Z}$ & $\mathrm{x}_{1}$ & $\mathrm{x}_{2}$ & $\mathrm{~S}_{1}$ & $\mathrm{~S}_{2}$ & $\mathrm{RHS}$ \\
\hline $\mathrm{Z}$ & 1 & -25 & -30 & 0 & 0 & $=$ \\
\hline
\end{tabular}




\begin{tabular}{llllllll}
\hline \multicolumn{3}{l}{$\begin{array}{l}\text { Basic } \\
\text { Variable }\end{array}$} & & \multicolumn{5}{l}{ Basic variable Basic variable } \\
\hline $\mathrm{S}_{1}$ & 0 & 20 & 30 & 1 & 0 & $=$ & 690 \\
\hline $\mathrm{S}_{2}$ & 0 & 5 & 4 & 0 & 1 & $=$ & 120 \\
\hline
\end{tabular}

3. Optimality Test: We need to determine if an adjacent intersection point improves the value of the objective function. If not, the current extreme point is optimal. If an improvement is possible, the optimality test determines which variable currently in the independent set (having value zero) should enter the dependent set as a basic variable and become nonzero. For our maximization problem, we look at the Z-Row (The row marked by the basic variable $Z$ ). If any coefficients in that row are negative then we select the variable whose coefficient is the most negative as the entering variable.

\begin{tabular}{|c|c|c|c|c|c|c|c|}
\hline & \multicolumn{3}{|c|}{$\begin{array}{l}\text { Basic } \\
\text { Variable }\end{array}$} & \multicolumn{4}{|c|}{ Basic variable Basic variable } \\
\hline & Z & $x_{1}$ & $x_{2}$ & $\mathrm{~S}_{1}$ & $\mathrm{~S}_{2}$ & & RHS \\
\hline Z & 1 & -25 & -30 & 0 & 0 & $=$ & 0 \\
\hline $\mathrm{S}_{1}$ & 0 & 20 & 30 & 1 & 0 & $=$ & 690 \\
\hline $\mathrm{S}_{2}$ & 0 & 5 & 4 & 0 & 1 & $=$ & 120 \\
\hline
\end{tabular}

In the Z-Row the coefficients are:

\begin{tabular}{llllll}
\hline & $Z$ & $x_{1}$ & $x_{2}$ & $S_{1}$ & $S_{2}$ \\
\hline$Z$ & 1 & -25 & -30 & 0 & 0 \\
\hline
\end{tabular}

The variable with the most negative coefficient is $x_{2}$ with value -30 . Thus, $x_{2}$ wants to become a basic variable. We can only have three basic variables in this example (because we have three equations) so one of the current basic variables $\left\{S_{1}, S_{2}\right\}$ must be replaced by $x_{2}$. Let's proceed to see how we determine which variable exists being a basic variable.

4. Feasibility Test: To find a new intersection point, one of the variables in the basic variable set must exit to allow the entering variable from Step 3 to become basic. The feasibility test determines which current dependent variable to choose for exiting, ensuring we stay inside the feasible region. We will use the minimum positive ratio test as our feasibility test. The Minimum Positive Ratio test is the MIN( $\left.\mathrm{RHS}_{\mathrm{j}} / \mathrm{a}_{\mathrm{j}}>0\right)$. Make a quotient of the $\frac{r h s_{j}}{a_{j}}$. 


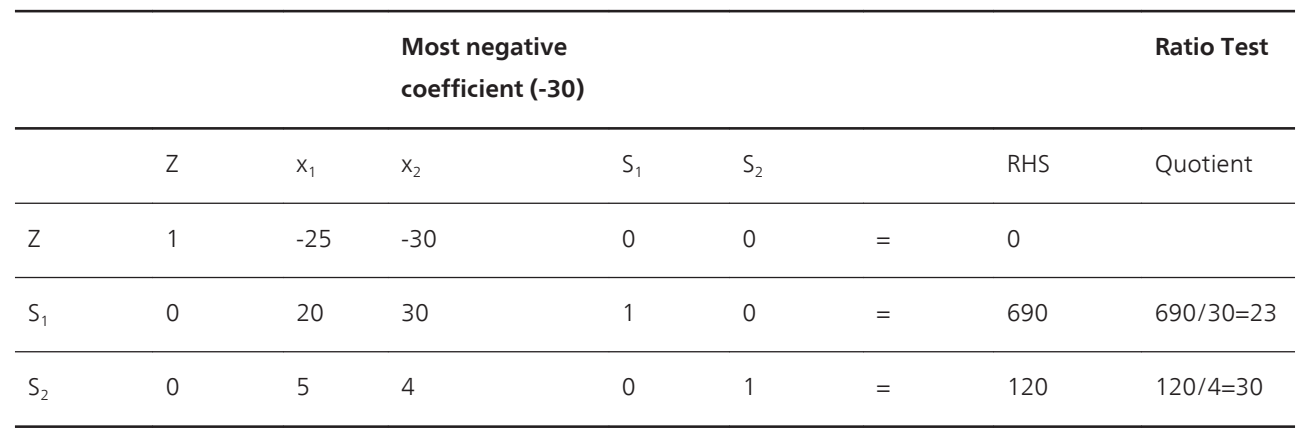

Note that we will always disregard all quotients with either 0 or negative values in the denominator. In our example we compare $\{23,30\}$ and select the smallest non-negative value. This gives the location of the matrix pivot that we will perform.

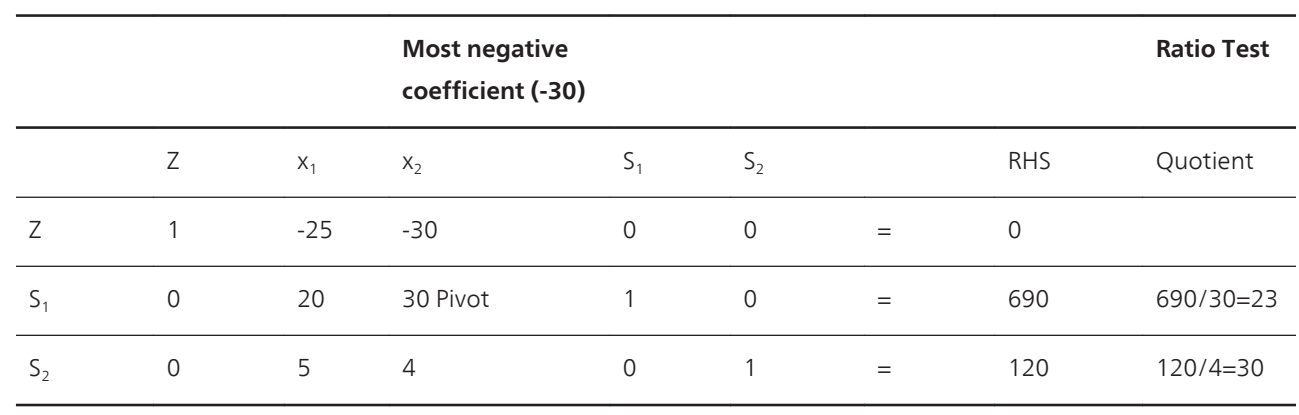

5. Pivot: We can form a new equivalent system by using row operations to change the pivot element to 1 and all other numbers in the pivot column to zero. We do the row operations by adding a suitable multiple of the pivot row to a multiple of each row in the tableau, thus eliminating the new basic variable. Then set the new non-basic variables to zero in the new system to find the values of the new basic variables, thereby determining an intersection point.

\begin{tabular}{|c|c|c|c|c|c|c|c|c|}
\hline & & & $\begin{array}{l}\text { Pivot } \\
\text { Column }\end{array}$ & & & & & \\
\hline & Z & $x_{1}$ & $x_{2}$ & $\mathrm{~S}_{1}$ & $\mathrm{~S}_{2}$ & & RHS & \\
\hline Z & 1 & -25 & -30 & 0 & 0 & $=$ & 0 & \\
\hline $\mathrm{S}_{1}$ & $0 / 30$ & $20 / 30$ & $30 / 30$ & $1 / 30$ & $0 / 30$ & $=$ & $690 / 30$ & Pivot Row \\
\hline $\mathrm{S}_{2}$ & 0 & 5 & 4 & 0 & 1 & $=$ & 120 & \\
\hline
\end{tabular}


Make the entry in the intersection of the pivot column and pivot row equal to 1.

\begin{tabular}{|c|c|c|c|c|c|c|c|c|}
\hline & & & $\begin{array}{l}\text { Pivot } \\
\text { Column }\end{array}$ & & & & & \\
\hline & Z & $x_{1}$ & $x_{2}$ & $\mathrm{~S}_{1}$ & $\mathrm{~S}_{2}$ & & RHS & \\
\hline Z & 1 & -25 & -30 & 0 & 0 & $=$ & 0 & \\
\hline$S_{1}$ & 0 & $2 / 3$ & 1 & $1 / 30$ & $0 /$ & $=$ & 23 & Pivot Row \\
\hline $\mathrm{S}_{2}$ & 0 & 5 & 4 & 0 & 1 & $=$ & 120 & \\
\hline
\end{tabular}

Using row operations make all other entries in the pivot column equal to 0 .

\begin{tabular}{ccccccccc}
\hline \multicolumn{7}{c}{ Pivot Column } \\
\hline$Z$ & $Z$ & $x_{1}$ & $x_{2}$ & $S_{1}$ & $S_{2}$ & & RHS \\
\hline$Z$ & 1 & -5 & 0 & 1 & 0 & $=$ & 690 & $30 R_{2}+R_{1} a R_{1}$ \\
\hline$x_{2}$ & 0 & $2 / 3$ & 1 & $1 / 30$ & 0 & $=$ & 23 & \\
\hline$S_{2}$ & 0 & $7 / 3$ & 0 & $-4 / 30$ & 1 & $=$ & 28 & $-4 R_{2}+R_{3} a ̀ R_{3}$ \\
\hline
\end{tabular}

Let's interpret our current basic feasible solution.

Basic Variables:

$\mathrm{x}_{2}=23$

$\mathrm{S}_{2}=32$

$\mathrm{Z}=690$

Non-Basic Variables $x_{1}=0, S_{1}=0$

6. Repeat Steps 3-5 until an optimal extreme point is found.

We note that $x_{1}$ has a coefficient of -5 in the Z-Row therefore, we are not optimal.

Step 3.

\begin{tabular}{|c|c|c|c|c|c|c|c|}
\hline & & \multicolumn{6}{|c|}{$\begin{array}{l}\text { Negative } \\
\text { Coefficient }\end{array}$} \\
\hline & Z & $x_{1}$ & $x_{2}$ & $\mathrm{~S}_{1}$ & $\mathrm{~S}_{2}$ & & RHS \\
\hline Z & 1 & -5 & 0 & 1 & 0 & $=$ & 690 \\
\hline$x_{2}$ & 0 & $2 / 3$ & 1 & $1 / 30$ & 0 & $=$ & 23 \\
\hline $\mathrm{S}_{2}$ & 0 & $7 / 3$ & 0 & $-4 / 30$ & 1 & $=$ & 28 \\
\hline
\end{tabular}


Step 4.

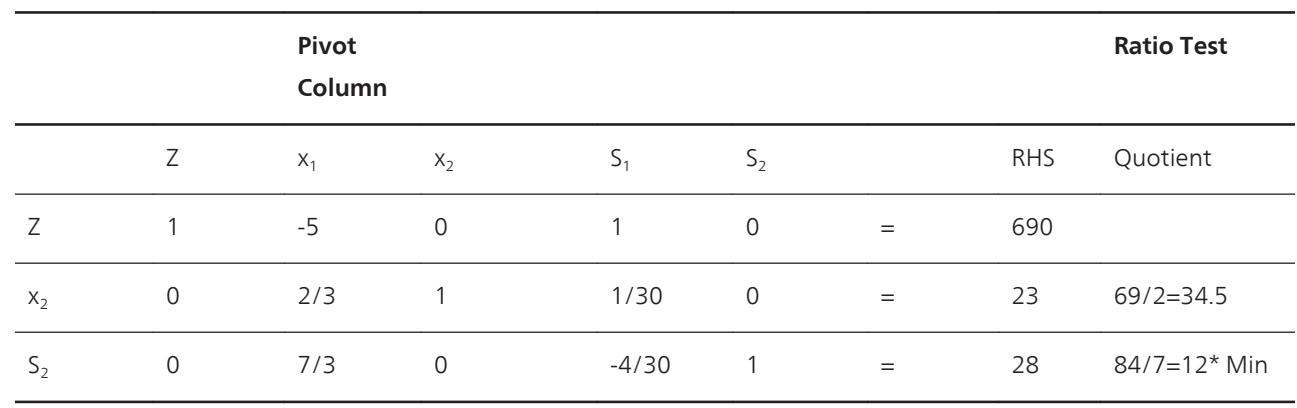

The minimum non-negative quotient is 12 . This indicates that to remain in the feasible region that $x_{1}$ enters as a basic variable and $S_{2}$ leaves being a basic variable.

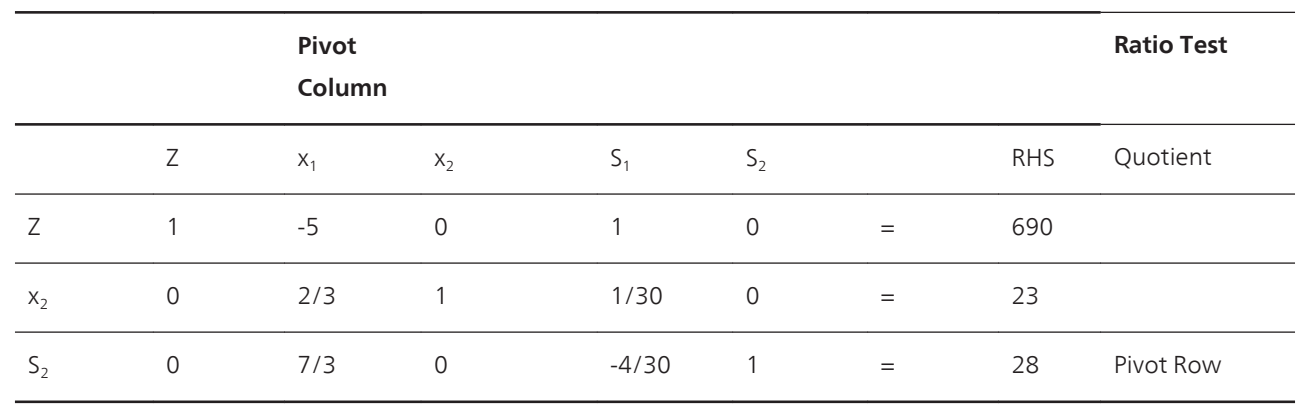

Step 5. We make the highlighted position a 1 and all other column entries 0 for the column of $x_{1}$. We divide the entire $S_{2}$ row by $7 / 3$.

\begin{tabular}{llllllll} 
& $\mathbf{Z}$ & $\mathbf{x}_{\mathbf{1}}$ & $\mathbf{x}_{\mathbf{2}}$ & $\mathbf{S}_{\mathbf{1}}$ & $\mathbf{S}_{\mathbf{2}}$ & \multicolumn{2}{l}{ RHS } \\
\hline $\mathrm{Z}$ & 1 & -5 & 0 & 1 & 0 & $=$ & 690 \\
\hline $\mathrm{X}_{2}$ & 0 & $2 / 3$ & 1 & $1 / 30$ & 0 & $=$ & 23 \\
\hline $\mathrm{S}_{2}$ & 0 & 1 & 0 & $-12 / 210$ & $3 / 7$ & $=$ & 12 \\
\hline
\end{tabular}

\begin{tabular}{lllllllll} 
& $\mathbf{Z}$ & $\mathbf{x}_{\mathbf{1}}$ & $\mathbf{x}_{\mathbf{2}}$ & $\mathbf{S}_{\mathbf{1}}$ & $\mathbf{S}_{\mathbf{2}}$ & \multicolumn{3}{c}{ RHS } \\
\hline $\mathrm{Z}$ & 1 & 0 & 0 & $5 / 7$ & $15 / 7$ & $=$ & 750 & $5 \mathrm{R}_{3}+\mathrm{R}_{1} \mathrm{àR}_{1}$ \\
\hline $\mathrm{x}_{2}$ & 0 & 0 & 1 & $1 / 14$ & $-2 / 7$ & $=$ & 15 & $-2 / 3 \mathrm{R}_{3}+\mathrm{R}_{2} \mathrm{àR} \mathrm{R}_{2}$ \\
\hline $\mathrm{x}_{1}$ & 0 & 1 & 0 & $-2 / 35$ & $3 / 7$ & $=$ & 12 & \\
\hline
\end{tabular}


The current solution is read as follows:

Basic Variables

$\mathrm{x}_{2}=15$

$\mathrm{x}_{1}=12$

$\mathrm{Z}=750$

Non-basic variables

$\mathrm{S}_{1}=\mathrm{S}_{2}=0$

There are no negative coefficients in the Z-Row, so we are optimal.

\begin{tabular}{llllll} 
& $\mathbf{Z}$ & $\mathbf{x}_{1}$ & $\mathbf{x}_{2}$ & $\mathbf{S}_{1}$ & $\mathbf{S}_{2}$ \\
\hline $\mathbf{Z}$ & 1 & 0 & 0 & $5 / 7$ & $15 / 7$ \\
\hline
\end{tabular}

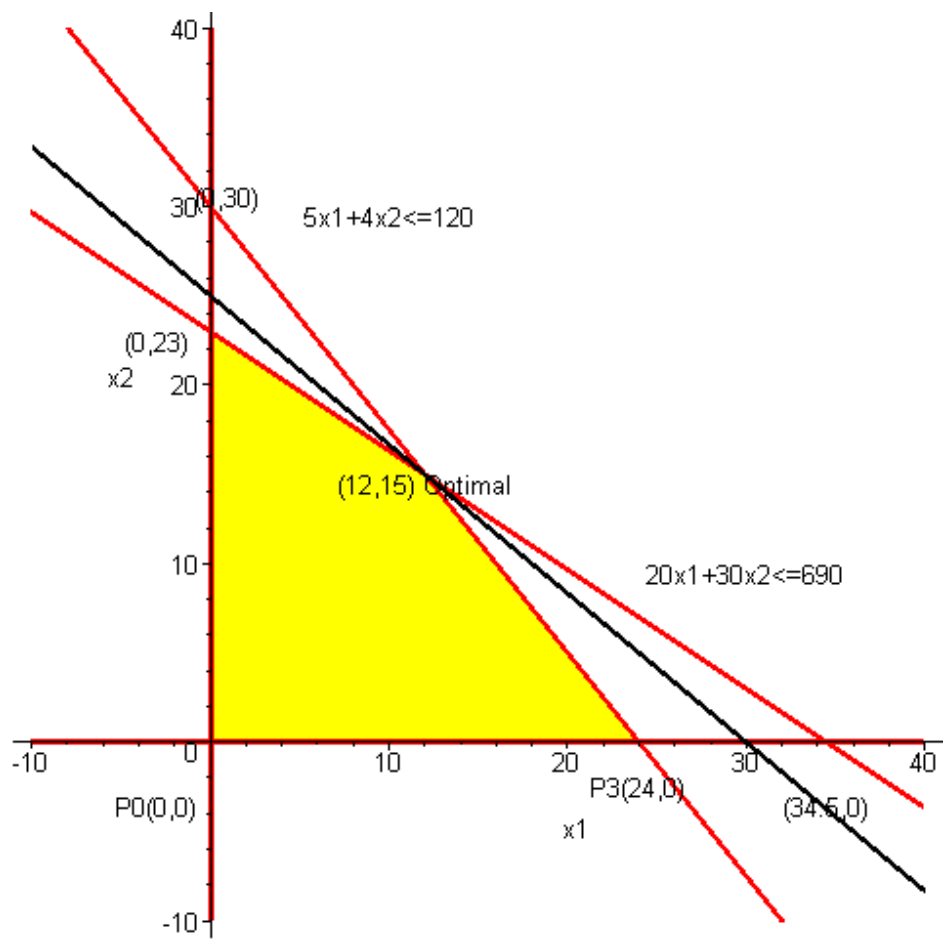

Figure 5. The set of points satisfying the constraint of this linear programming problem (the convex set as a shaded region) 
Each solution found in the tableau corresponds to a corner point. We went from corner $(0,0)$ to corner $(0,23)$ to corner $(12,15)$.

Maximize $\mathrm{Z}=3 \mathrm{x}_{1}+\mathrm{x}_{2}$

Subject to:

$2 \mathrm{x}_{1}+\mathrm{x}_{2} \leq 6$

$x_{1}+3 x_{2} \leq 9$

$\mathrm{x}_{1}, \mathrm{x}_{2} \geq 0$

The Tableau Format with slack variables $y_{1}, y_{2}$ :

\begin{tabular}{lllllll} 
Basic Var. & $\mathbf{Z}$ & $\mathbf{x}_{\mathbf{1}}$ & $\mathbf{x}_{\mathbf{2}}$ & $\mathbf{y}_{\mathbf{1}}$ & $\mathbf{y}_{\mathbf{2}}$ & RHS \\
\hline $\mathrm{Z}$ & 1 & -3 & -1 & 0 & 0 & 0 \\
\hline $\mathrm{y}_{1}$ & 0 & 2 & 1 & 1 & 0 & 6 \\
\hline $\mathrm{y}_{2}$ & 0 & 1 & 3 & 0 & 1 & 9
\end{tabular}

Basic variable $\left\{Z, y_{1}, y_{2}\right\}$

Non-basic Variable $\left\{x_{x 1, x 2}\right\}$

Extreme Point $(0,0)$---Corresponding to the values of $\left(x_{1}, x_{2}\right)$

Value of objective function: $Z=0$

Optimality Test: The entering variable is $x_{1}$ (corresponding to -3 in the Z- row.)

Feasibility Test: Compute the ratios of the "RHS" divided by the column labeled $x_{1}$ to determine the minimum positive ratio.

\begin{tabular}{llllllll} 
Basic Var. & $\mathbf{Z}$ & $\mathbf{x}_{\mathbf{1}}$ & $\mathbf{x}_{\mathbf{2}}$ & $\mathbf{y}_{\mathbf{1}}$ & $\mathbf{y}_{\mathbf{2}}$ & $\mathbf{R H S}$ & Quotient \\
\hline $\mathrm{Z}$ & 1 & -3 & -1 & 0 & 0 & 0 & $6 / 2=3$ \\
\hline $\mathrm{y}_{1}$ & 0 & 2 & 1 & 1 & 0 & 6 & $9 / 1=9$
\end{tabular}

Choose $y_{1}$ to leave since it corresponds to the minimum positive ratio test value of 3 .

Pivot: Divide the row containing the exiting variable (the first row in this case) by the coefficient of the entering variable in that row (the coefficient of $x_{1}$ in this case), giving a coefficient of 1 for the entering variable in this row. Then eliminate the entering variable $x_{1}$ from the remaining rows (which do not contain the exiting variable $\mathrm{y}_{1}$ and have a zero coefficient for it). The results are summarized in the next tableau. 


\begin{tabular}{lllllll} 
Basic Var. & $\mathbf{Z}$ & $\mathbf{x}$ & $\mathbf{x}_{2}$ & $\mathbf{y}_{1}$ & $\mathbf{y}_{2}$ & RHS \\
\hline $\mathrm{Z}$ & 1 & 0 & 0.5000 & 1.5 & 0 & 9 \\
\hline $\mathrm{x}_{1}$ & 0 & 1 & 0.5000 & .5 & 0 & 3 \\
\hline$y_{2}$ & 0 & 0 & 2.5000 & -.5 & 1 & 6
\end{tabular}

Basic variable $\left\{Z, x_{1}, y 2\right\}$

Non-basic Variable $\left\{y_{1}, x_{2}\right\}$

Extreme Point $(3,0)$---Corresponding to the values of $\left(x_{1}, x_{2}\right)$

Value of objective function: $Z=9$

The pivot determines that the dependent variables have the values $x_{1}=3, y_{2}=6$ and $Z=9$.

Optimality Test: There are no negative coefficients in the Z- row. Thus $x_{1}=3$ (a basic variable) and $x_{2}=0$ (a non-basic variable) is an extreme point giving the optimal objective function value $Z=9$.

We read the solution as $Z=9, x_{1}=3$, and $s_{2}=6$.

Remarks: We have assumed that the origin is a feasible extreme point. If it is not, then an extreme point must be found before the Simplex Method, as presented, can be used. We have also assumed that the linear program is not "degenerate" in the sense that no more than two constraints intersect at the same point. These and other topics are studied in more advanced optimization courses.

\section{Linear programming with technology}

Technology is critical to solving, analyzing, and performing sensitivity analysis on linear programming problems. Technology provides a suite of powerful, robust routines for solving optimization problems, including linear programs (LPs). Technology, that we briefly discuss, includes Excel, LINDO, and LINGO as these appear to be used often in engineering. We tested all these software packages and found them useful.

We present our previous example solved via each technology.

Maximize $Z=25 x_{1}+30 x_{2}$

Subject to:

$20 \mathrm{x}_{1}+30 \mathrm{x}_{2} \leq 6905$

$\mathrm{x}_{1}+4 \mathrm{x}_{2} \leq 120$

$x 1, x 2, \geq 0$ 


\section{EXCEL}

\begin{tabular}{|c|c|c|c|c|c|c|}
\hline 2 & A & B & C & D & $\mathrm{E}$ & $\mathrm{F}$ \\
\hline 1 & \multicolumn{2}{|c|}{ LP in EXCEL } & & & & \\
\hline \multicolumn{7}{|l|}{2} \\
\hline \multicolumn{7}{|l|}{3} \\
\hline 4 & Decision & Variables & & & \multicolumn{2}{|c|}{ Objective Function } \\
\hline 5 & & \multicolumn{2}{|c|}{ Initial/Final Values } & & \multicolumn{2}{|c|}{$=28 * \mathrm{~B} 6+30 * \mathrm{~B} 7$} \\
\hline 6 & $\mathrm{x} 1$ & 0 & & & & \\
\hline 7 & $x 2$ & 0 & & & & \\
\hline 8 & & & & & & \\
\hline 9 & & & & & & \\
\hline
\end{tabular}

\begin{tabular}{|c|c|c|c|c|c|c|}
\hline \multirow{2}{*}{\multicolumn{2}{|c|}{$=2 * B 6+3^{*} B 7$}} & \multicolumn{3}{|c|}{ Allgnment } & \multicolumn{2}{|r|}{$\sqrt{x}$} \\
\hline & & & & & & \\
\hline 4 & A & B & C & D & $E$ & $\mathrm{~F}$ \\
\hline 1 & \multicolumn{2}{|c|}{ LP in EXCEL } & & & & \\
\hline \multicolumn{7}{|c|}{2} \\
\hline \multicolumn{7}{|l|}{3} \\
\hline 4 & Decision & Variables & & & \multicolumn{2}{|c|}{ Objective Function } \\
\hline 5 & & \multicolumn{2}{|c|}{ Initial/Final Values } & & \multicolumn{2}{|l|}{0} \\
\hline 6 & $\mathrm{x} 1$ & \multicolumn{2}{|l|}{0} & & & \\
\hline 7 & $\mathrm{x} 2$ & \multicolumn{2}{|l|}{0} & & & \\
\hline \multicolumn{7}{|l|}{8} \\
\hline \multicolumn{7}{|l|}{9} \\
\hline 10 & \multicolumn{2}{|c|}{ Constraints } & & Used & RHS & \\
\hline 11 & & & & 0 & 100 & \\
\hline 12 & & & & 0 & 120 & \\
\hline 13 & & & & 0 & 90 & \\
\hline 14 & & & & & & \\
\hline 15 & & & & & . & \\
\hline
\end{tabular}




\section{Solver}

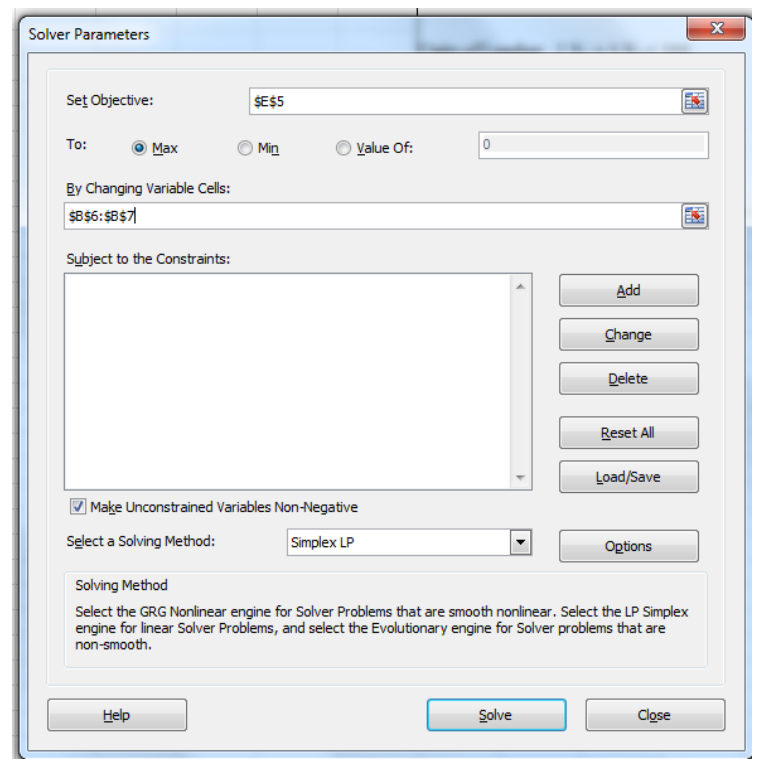

Constraints into solver

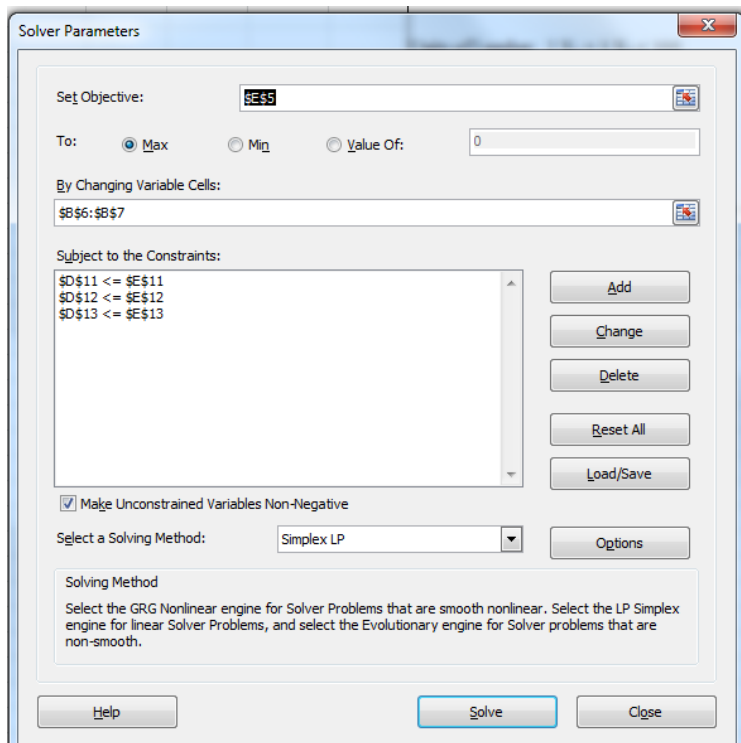




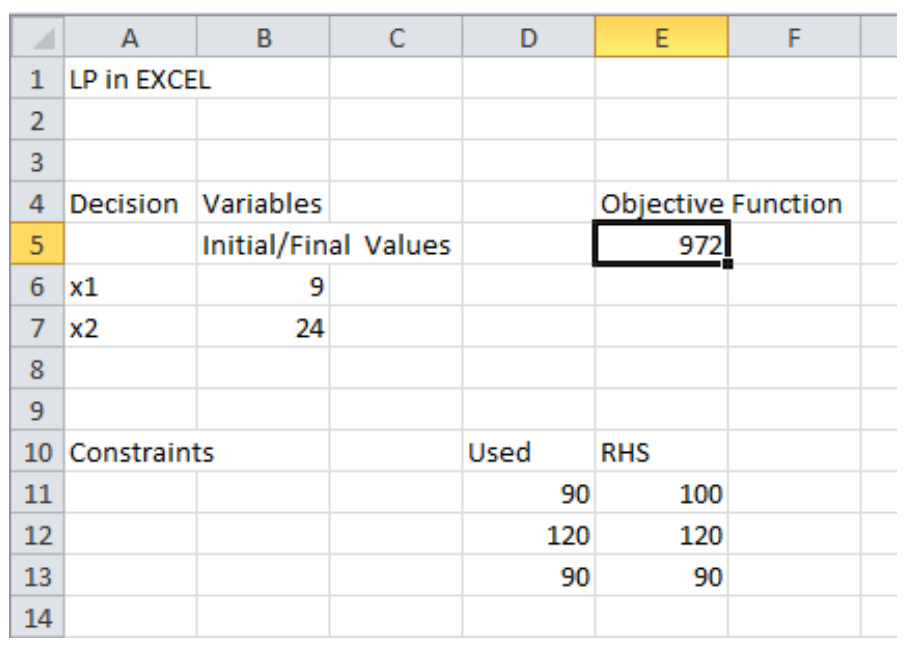

\section{Reports}

Answer Report

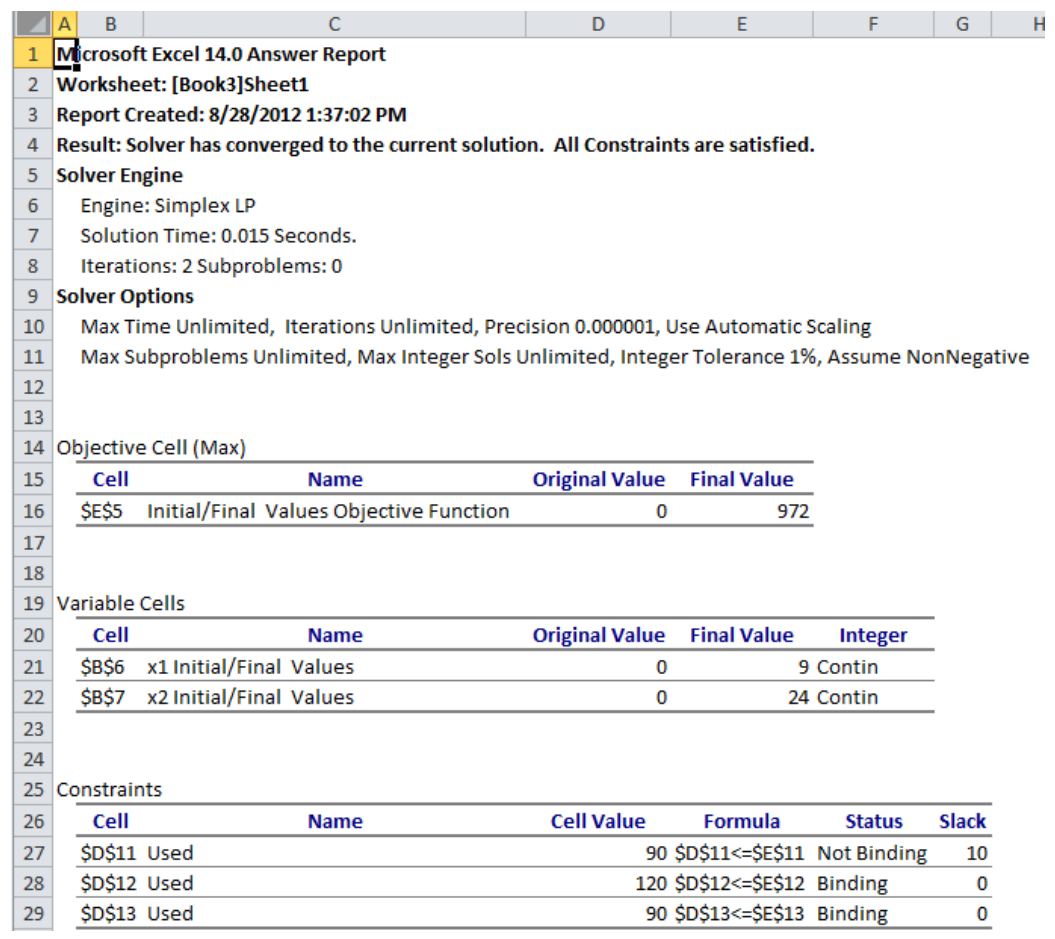


Sensitivity Report

\begin{tabular}{|c|c|c|c|c|c|c|c|}
\hline 4 & A & C & D & $E$ & $\mathrm{~F}$ & G & $\mathrm{H}$ \\
\hline 1 & \multicolumn{7}{|c|}{ Microsoft Excel 14.0 Sensitivity Report } \\
\hline 2 & \multicolumn{7}{|c|}{ Worksheet: [Book3]Sheet1 } \\
\hline 3 & \multicolumn{7}{|c|}{ Report Created: 8/28/2012 1:37:03 PM } \\
\hline 4 & & & & & & & \\
\hline 5 & & & & & & & \\
\hline 6 & \multicolumn{7}{|c|}{ Variable Cells } \\
\hline 7 & & & Final & Reduced & Objective & Allowable & Allowable \\
\hline 8 & Cell & Name & Value & Cost & Coefficient & Increase & Decrease \\
\hline 9 & $\$ B \$ 6$ & x1 Initial/Final Values & 9 & 0 & 28 & 6.285714286 & 8 \\
\hline 10 & $\$ B \$ 7$ & x2 Initial/Final Values & 24 & 0 & 30 & 12 & 5.5 \\
\hline 11 & & & & & & & \\
\hline 12 & \multicolumn{7}{|c|}{ Constraints } \\
\hline 13 & & & Final & Shadow & Constraint & Allowable & Allowable \\
\hline 14 & Cell & Name & Value & Price & R.H. Side & Increase & Decrease \\
\hline 15 & $\$ D \$ 11$ & Used & 90 & 0 & 100 & $1 \mathrm{E}+30$ & 10 \\
\hline 16 & $\$ D \$ 12$ & Used & 120 & 4.8 & 120 & 60 & 15 \\
\hline 17 & $\$ D \$ 13$ & Used & 90 & 4.4 & 90 & 10 & 30 \\
\hline
\end{tabular}

We find our solution is $x_{1}=9, x_{2}=24, P=\$ 972$. From the standpoint of sensitivity analysis Excel is satisfactory in that it provides shadow prices.

Limitation: No tableaus are provided making it difficult to find alternate solutions. 


\section{LINDO}

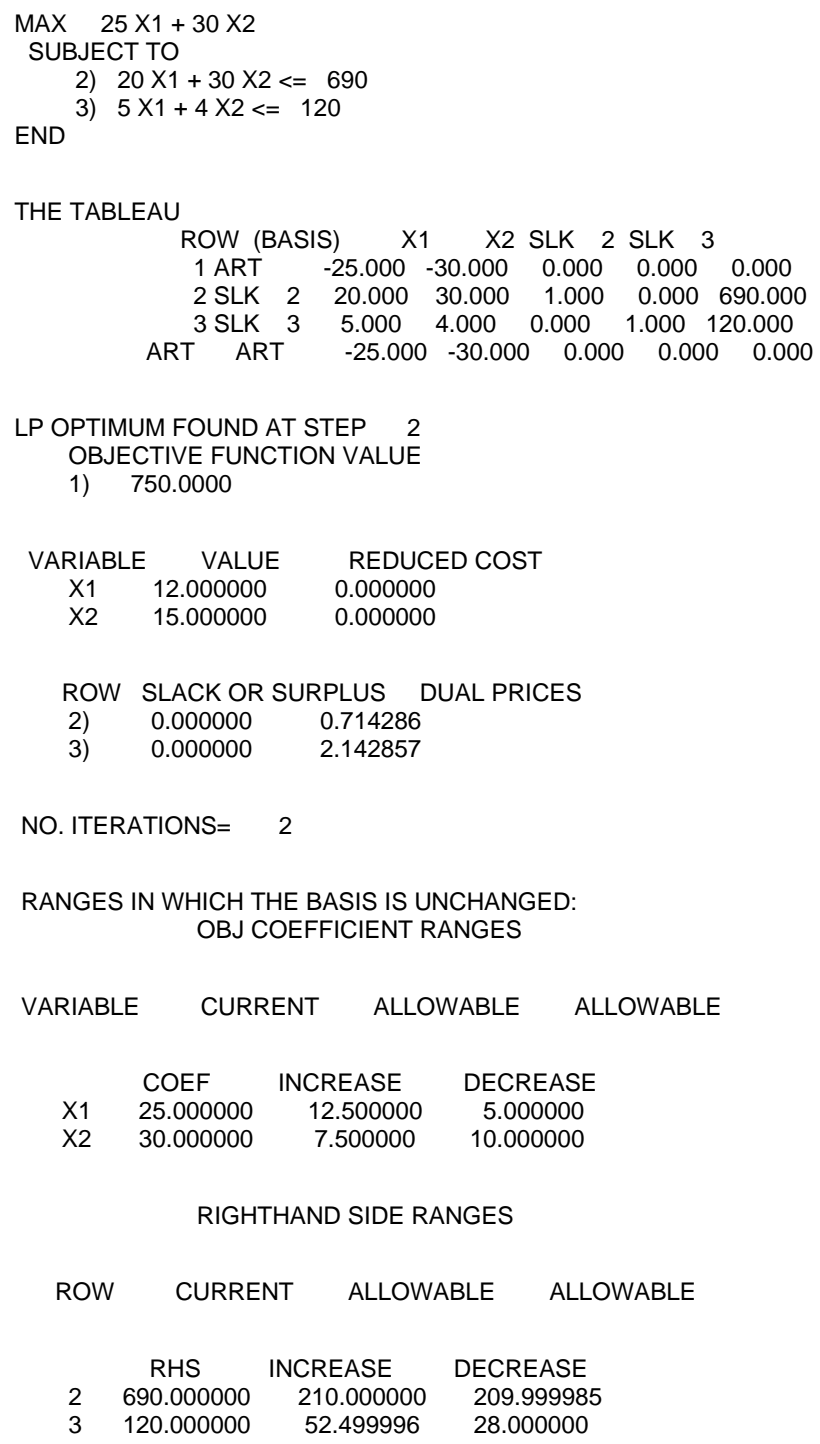

NO. ITERATIONS $=2$

RANGES IN WHICH THE BASIS IS UNCHANGED: OBJ COEFFICIENT RANGES

VARIABLE CURRENT ALLOWABLE ALLOWABLE

$\begin{array}{llcc} & \text { COEF } & \text { INCREASE } & \text { DECREASE } \\ \text { X1 } & 25.000000 & 12.500000 & 5.000000 \\ \text { X2 } & 30.000000 & 7.500000 & 10.000000\end{array}$

RIGHTHAND SIDE RANGES

ROW CURRENT ALLOWABLE ALLOWABLE

$\begin{array}{cccc} & \text { RHS } & \text { INCREASE } & \text { DECREASE } \\ 2 & 690.000000 & 210.000000 & 209.999985 \\ 3 & 120.000000 & 52.499996 & 28.000000\end{array}$

THE TABLEAU

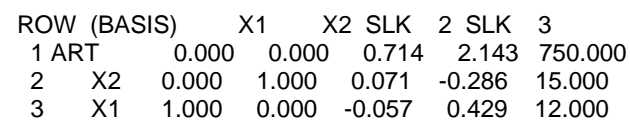




\section{LINGO}

MODEL:

$\operatorname{MAX}=25 * \times 1+30 * \times 2$

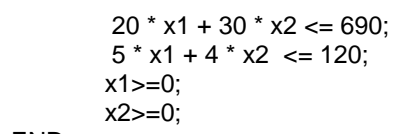

END

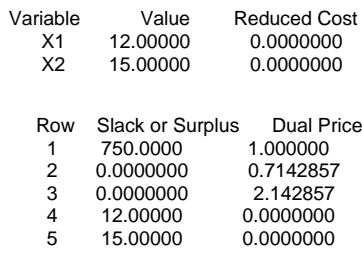

\section{Case study}

In our case study we present linear programming for supply chain design. We consider producing a new mixture of gasoline. We desire to minimize the total cost of manufacturing and distributing the new mixture. There is a supply chain involved with a product that must be modeled. The product is made up of components that are produced separately.

\begin{tabular}{llllll}
\hline Crude Oil type & Compound A (\%) Compound B (\%) & Compound C (\%) & Cost/Barrel & $\begin{array}{l}\text { Barrel Avail (000 } \\
\text { of barrels) }\end{array}$ \\
\hline X10 & 35 & 25 & 35 & $\$ 26$ & 15000 \\
\hline X20 & 50 & 30 & 15 & $\$ 32$ & 32000 \\
\hline X30 & 60 & 20 & 15 & $\$ 55$ & 24000 \\
\hline
\end{tabular}

Demand information is as follows:

\begin{tabular}{lllll}
\hline Gasoline & Compound A (\%) & Compound B (\%) & Compound C (\%) & $\begin{array}{l}\text { Expected Demand } \\
\text { (000 of barrels) }\end{array}$ \\
\hline Premium & $\geq 55$ & $\leq 23$ & 14000 \\
\hline Super & $\geq 25$ & $\leq 35$ & 22000 \\
\hline Regular & $\geq 40$ & $\leq 25$ & 25000 \\
\hline
\end{tabular}


Let $\mathrm{i}$ = crude type 1, 2, 3 (X10,X20,X30 respectively)

Let $\mathrm{j}$ = gasoline type 1, 2, 3 (Premium, Super, Regular respectively)

We define the following decision variables:

$G i j=$ amount of crude $\mathrm{i}$ used to produce gasoline $\mathrm{j}$

For example,

$G_{11}=$ amount of crudeX10used to produce Premium gasoline .

$G_{12}=$ amount of crude typeX20used to produce Premium gasoline

$G_{13}=$ amount of crude typeX30used to produce Premium gasoline

$G_{12}=$ amount of crude typeX10used to produce Super gasoline

$G_{22}=$ amount of crude typeX20used to produce Super gasoline

$G_{32}=$ amount of crude typeX30used to produce Super gasoline

$G_{13}=$ amount of crude typeX10used to produce Regular gasoline

$G_{23}=$ amount of crude typeX20used to produce Regular gasoline

$G_{33}=$ amount of crude typeX30used to produce Regular gasoline

LP formulation

Minimize Cost $=\$ 86(\mathrm{G} 11+\mathrm{G} 21+\mathrm{G} 31)+\$ 92(\mathrm{G} 12+\mathrm{G} 22+\mathrm{G} 32)+\$ 95(\mathrm{G} 13+\mathrm{G} 23+\mathrm{G} 33)$

Subject to: Demand

G11+G21+G31>14000 (Premium)

$\mathrm{G} 12+\mathrm{G} 22+\mathrm{G} 32>22000$ (Super)

G13+G23+G33>25000 (Regular)

Availability of products

$\mathrm{G} 11+\mathrm{G} 12+\mathrm{G} 13<15000$ (crude 1)

$\mathrm{G} 21+\mathrm{G} 22+\mathrm{G} 23<32000$ (crude 2)

$\mathrm{G} 31+\mathrm{G} 32+\mathrm{G} 33<24000$ (crude 3)

Product mix in mixture format

$(0.35 G 11+0.50 G 21+0.60 G 31) /(G 11+G 21+G 31) \geq 0.55(X 10$ in Premium $)$

$(0.25 G 11+0.30 G 21+0.20 G 31) /(G 11+G 21+G 31) \leq 0.23(X 20$ in Premium $)$

$(0.35 G 13+0.15 G 23+0.15 G 33) /(G 13+G 23+G 33) \geq 0.25$ (X 20 in Regular $)$

$(0.35 G 13+0.15 G 23+0.15 G 33) /(G 13+G 23+G 33) \leq 0.35$ (X30 in Regular)

$(0.35 G 12+0.50 G 22+0.60 G 23) /(G 12+G 22+G 32) \leq 0.40$ (Compound X 10 in Super)

$(0.35 G 12+0.15 G 22+0.15 G 32) /(G 12+G 22+G 32) \leq 0.25$ (Compound X30 in Super)

The solution was found using LINDO and we noticed an alternate optimal solution. Two solutions are found yielding a minimum cost of $\$ 1,904,000$. 


\begin{tabular}{lll}
\hline Decision variable & $Z=\$ 1,940,000$ & $Z=\$ 1,940,000$ \\
\hline$G_{11}$ & 0 & 1,400 \\
\hline$G_{12}$ & 0 & 3,500 \\
\hline$G_{13}$ & 14,000 & 9,100 \\
\hline$G_{21}$ & 15,000 & 1,100 \\
\hline$G_{22}$ & 7,000 & 20,900 \\
\hline$G_{23}$ & 0 & 0 \\
\hline$G_{31}$ & 0 & 12,500 \\
\hline$G_{32}$ & 25,000 & 7,500 \\
\hline$G_{33}$ & 0 & 4,900 \\
\hline
\end{tabular}

Depending on whether we want to additionally minimize delivery (across different locations) or maximize sharing by having more distribution point involved then we have choices.

We present one of the solutions below with LINDO.

\begin{tabular}{ccc}
\hline & LP OPTIMUM FOUND AT STEP 7 \\
OBJECTIVE FUNCTION VALUE & \\
1) & $\mathbf{1 9 0 4 0 0 0 .}$ & \\
VARIABLE & VALUE & REDUCED COST \\
\hline P1 & 0.000000 & 0.000000 \\
R1 & 15000.000000 & 0.000000 \\
E1 & 0.000000 & 0.000000 \\
P2 & 0.000000 & 0.000000 \\
R2 & 7000.000000 & 0.000000 \\
E2 & 25000.000000 & 0.000000 \\
P3 & 14000.000000 & 0.000000 \\
R3 & 0.000000 & 0.000000 \\
E3 & 0.000000 & 0.000000 \\
\hline
\end{tabular}




\begin{tabular}{ccc}
\hline ROW & SLACK OR SURPLUS & DUAL PRICES \\
\hline 2$)$ & 0.000000 & 9.000000 \\
$3)$ & 0.000000 & 3.000000 \\
$4)$ & 10000.000000 & 0.000000 \\
5) & 0.000000 & -35.000000 \\
6) & 0.000000 & -35.000000 \\
$7)$ & 0.000000 & -35.0000000 \\
8) & 700.000000 & 0.000000 \\
$9)$ & 3500.000000 & 0.000000 \\
$10)$ & 1400.000000 & 0.000000 \\
$11)$ & 2500.000000 & 0.000000 \\
$12)$ & 2500.000000 & 0.000000 \\
$13)$ & 420.000000 & 0.000000 \\
\hline
\end{tabular}

NO. ITERATIONS $=7$

RANGES IN WHICH THE BASIS IS UNCHANGED:

OBJ COEFFICIENT RANGES

\begin{tabular}{cccc} 
VARIABLE & CURRENT & ALLOWABLE & ALLOWABLE \\
& COEF & INCREASE & DECREASE \\
\hline P1 & 26.000000 & INFINITY & 0.000000 \\
R1 & 26.000000 & 0.000000 & INFINITY \\
E1 & 26.000000 & INFINITY & 0.000000 \\
P2 & 32.000000 & 0.000000 & 0.000000 \\
R2 & 32.000000 & 0.000000 & 0.000000 \\
E2 & 32.000000 & 0.000000 & 35.000000 \\
P3 & 35.000000 & 0.0000000 & 3.000000 \\
R3 & 35.000000 & INFINITY & 0.000000 \\
E3 & 35.000000 & INFINITY & 0.000000 \\
\hline
\end{tabular}




\begin{tabular}{cccc}
\hline ROW & \multicolumn{2}{c}{ RIGHTHAND SIDE RANGES } & \\
& CURRENT & ALLOWABLE & ALLOWABLE \\
\hline 2 & RHS & INCREASE & DECREASE \\
\hline 3 & 15000.000000 & 4200.000000 & 0.000000 \\
4 & 32000.000000 & 4200.000000 & 0.000000 \\
5 & 24000.000000 & INFINITY & 10000.000000 \\
6 & 14000.0000000 & 10000.000000 & 14000.000000 \\
7 & 22000.000000 & 0.000000 & 4200.000000 \\
8 & 25000.0000000 & 0.000000 & 4200.000000 \\
9 & 0.000000 & 700.000000 & INFINITY \\
10 & 0.000000 & 3500.000000 & INFINITY \\
11 & 0.000000 & INFINITY & 1400.000000 \\
12 & 0.000000 & 2500.000000 & INFINITY \\
13 & 0.000000 & INFINITY & 2500.000000 \\
\hline & 0.000000 & INFINITY & 420.000000 \\
\hline
\end{tabular}

THE TABLEAU

\begin{tabular}{|c|c|c|c|c|c|c|c|c|c|}
\hline ROW & (BASIS) & & P1 & R1 & E1 & P2 & R2 & E2 & \\
\hline 1 & & ART & & 0.000 & 0.000 & 0.000 & 0.000 & 0.000 & 0.000 \\
\hline 2 & & R1 & & 1.000 & 1.000 & 1.000 & 0.000 & 0.000 & 0.000 \\
\hline 3 & & P2 & & 1.000 & 0.000 & 0.000 & 1.000 & 0.000 & 0.000 \\
\hline 4 & & SLK & & 4 & 0.000 & 0.000 & 0.000 & 0.000 & 0.000 \\
\hline 5 & & P3 & & 0.000 & 0.000 & 0.000 & 0.000 & 0.000 & 0.000 \\
\hline 6 & & $\mathrm{R} 2$ & & -1.000 & 0.000 & -1.000 & 0.000 & 1.000 & 0.000 \\
\hline 7 & & E2 & & 0.000 & 0.000 & 1.000 & 0.000 & 0.000 & 1.000 \\
\hline 8 & & SLK & & 8 & 0.150 & 0.000 & 0.000 & 0.000 & 0.000 \\
\hline 9 & & SLK & & 9 & -0.500 & 0.000 & -0.500 & 0.000 & 0.000 \\
\hline 10 & & SLK & & 10 & -0.200 & 0.000 & -0.200 & 0.000 & 0.000 \\
\hline 11 & & SLK & & 11 & 0.000 & 0.000 & 0.150 & 0.000 & 0.000 \\
\hline 12 & & SLK & & 12 & 0.000 & 0.000 & 0.200 & 0.000 & 0.000 \\
\hline 13 & & SLK & & 13 & -0.050 & 0.000 & 0.000 & 0.000 & 0.000 \\
\hline
\end{tabular}




\begin{tabular}{|c|c|c|c|c|c|c|c|}
\hline ROW & P3 & R3 & E3 & SLK 2 & SLK 3 & SLK 4 & SLK 5 \\
\hline 1 & 0.000 & 0.000 & 0.000 & 9.000 & 3.000 & 0.000 & 35.000 \\
\hline 2 & 0.000 & 0.000 & 0.000 & 1.000 & 0.000 & 0.000 & 0.000 \\
\hline 3 & 0.000 & -1.000 & -1.000 & 1.000 & 1.000 & 0.000 & 0.000 \\
\hline 4 & 0.000 & 0.000 & 0.000 & 1.000 & 1.000 & 1.000 & 1.000 \\
\hline 5 & 1.000 & 1.000 & 1.000 & -1.000 & -1.000 & 0.000 & -1.000 \\
\hline 6 & 0.000 & 1.000 & 0.000 & -1.000 & 0.000 & 0.000 & 0.000 \\
\hline 7 & 0.000 & 0.000 & 1.000 & 0.000 & 0.000 & 0.000 & 0.000 \\
\hline 8 & 0.000 & 0.100 & 0.100 & -0.100 & -0.100 & 0.000 & -0.050 \\
\hline 9 & 0.000 & 1.000 & 0.000 & -0.500 & 0.000 & 0.000 & 0.000 \\
\hline 10 & 0.000 & 0.000 & 0.000 & -0.200 & 0.000 & 0.000 & 0.000 \\
\hline 11 & 0.000 & 0.000 & -0.100 & 0.000 & 0.000 & 0.000 & 0.000 \\
\hline 12 & 0.000 & 0.000 & 0.000 & 0.000 & 0.000 & 0.000 & 0.000 \\
\hline 13 & 0.000 & 0.100 & 0.100 & -0.100 & -0.100 & 0.000 & -0.030 \\
\hline ROW & SLK 6 & SLK 7 & SLK 8 & SLK 9 & SLK 10 & SLK 11 & SLK 12 \\
\hline 1 & 35.000 & 35.000 & 0.000 & 0.000 & 0.000 & 0.000 & 0.000 \\
\hline 2 & 0.000 & 0.000 & 0.000 & 0.000 & 0.000 & 0.000 & 0.000 \\
\hline 3 & 1.000 & 1.000 & 0.000 & 0.000 & 0.000 & 0.000 & 0.000 \\
\hline 4 & 1.000 & 1.000 & 0.000 & 0.000 & 0.000 & 0.000 & 0.000 \\
\hline 5 & -1.000 & -1.000 & 0.000 & 0.000 & 0.000 & 0.000 & 0.000 \\
\hline 6 & -1.000 & 0.000 & 0.000 & 0.000 & 0.000 & 0.000 & 0.000 \\
\hline 7 & 0.000 & -1.000 & 0.000 & 0.000 & 0.000 & 0.000 & 0.000 \\
\hline 8 & -0.100 & -0.100 & 1.000 & 0.000 & 0.000 & 0.000 & 0.000 \\
\hline 9 & -0.500 & 0.000 & 0.000 & 1.000 & 0.000 & 0.000 & 0.000 \\
\hline 10 & -0.200 & 0.000 & 0.000 & 0.000 & 1.000 & 0.000 & 0.000 \\
\hline 11 & 0.000 & -0.100 & 0.000 & 0.000 & 0.000 & 1.000 & 0.000 \\
\hline 12 & 0.000 & -0.100 & 0.000 & 0.000 & 0.000 & 0.000 & 1.000 \\
\hline 13 & -0.100 & -0.100 & 0.000 & 0.000 & 0.000 & 0.000 & 0.000 \\
\hline
\end{tabular}




\begin{tabular}{ccc}
\hline ROW & \multicolumn{2}{c}{ SLK 13 } \\
\hline 1 & $0.00 \mathrm{E}+00$ & $-0.19 \mathrm{E}+07$ \\
2 & 0.000 & 15000.000 \\
3 & 0.000 & 0.000 \\
4 & 0.000 & 10000.000 \\
5 & 0.000 & 14000.000 \\
6 & 0.000 & 7000.000 \\
7 & 0.000 & 25000.000 \\
8 & 0.000 & 700.000 \\
9 & 0.000 & 3500.000 \\
10 & 0.000 & 1400.000 \\
11 & 0.000 & 2500.000 \\
12 & 0.000 & 2500.000 \\
13 & 1.000 & 420.000 \\
\hline
\end{tabular}

LP OPTIMUM FOUND AT STEP 7

\section{OBJECTIVE FUNCTION VALUE}

1)

VARIABLE

P1

R1

E1

P2

R2

E2

P3

R3

E3

1904000.

\section{VALUE}

0.000000

15000.000000

0.000000

0.000000

7000.000000

25000.000000

14000.000000

0.000000

0.000000

\section{REDUCED COST}

0.000000

0.000000

0.000000

0.000000

0.000000

0.000000

0.000000

0.000000

0.000000 


\begin{tabular}{ccc}
\hline ROW & SLACK OR SURPLUS & DUAL PRICES \\
\hline 2$)$ & 0.000000 & 9.000000 \\
$3)$ & 0.000000 & 3.000000 \\
$4)$ & 10000.000000 & 0.000000 \\
$5)$ & 0.000000 & -35.000000 \\
$6)$ & 0.000000 & -35.000000 \\
$7)$ & 0.000000 & -35.000000 \\
$8)$ & 700.000000 & 0.000000 \\
$9)$ & 3500.000000 & 0.000000 \\
$10)$ & 1400.000000 & 0.000000 \\
$11)$ & 2500.000000 & 0.000000 \\
$12)$ & 2500.000000 & 0.000000 \\
$13)$ & 420.000000 & 0.000000 \\
\hline
\end{tabular}

NO. ITERATIONS $=7$

RANGES IN WHICH THE BASIS IS UNCHANGED:

OBJ COEFFICIENT RANGES

\begin{tabular}{cccc} 
VARIABLE & $\begin{array}{c}\text { CURRENT } \\
\text { COEF }\end{array}$ & ALLOWABLE & ALLOWABLE \\
\hline INCREASE & DECREASE \\
\hline R1 & 26.000000 & INFINITY & 0.000000 \\
E1 & 26.000000 & 0.000000 & INFINITY \\
P2 & 26.000000 & INFINITY & 0.000000 \\
R2 & 32.000000 & 0.000000 & 0.000000 \\
E2 & 32.000000 & 0.000000 & 0.000000 \\
P3 & 32.000000 & 0.000000 & 35.000000 \\
R3 & 35.000000 & 0.000000 & 3.000000 \\
E3 & 35.000000 & INFINITY & 0.000000 \\
\hline
\end{tabular}




\begin{tabular}{cccc}
\hline ROW & CURRENT & ALLOWABLE & ALLOWABLE \\
RHS & 15000.000000 & INCREASE & 0.000000 \\
\hline 2 & 32000.000000 & 4200.000000 & 0.000000 \\
\hline 3 & 24000.000000 & 4200.000000 & 10000.000000 \\
5 & 14000.000000 & INFINITY & 14000.000000 \\
6 & 22000.000000 & 10000.000000 & 4200.000000 \\
7 & 25000.000000 & 0.000000 & 4200.000000 \\
8 & 0.000000 & 0.000000 & INFINITY \\
9 & 0.000000 & 700.000000 & INFINITY \\
10 & 0.000000 & 3500.000000 & 1400.000000 \\
11 & 0.000000 & INFINITY & INFINITY \\
12 & 0.000000 & 2500.000000 & 2500.000000 \\
\hline
\end{tabular}

THE TABLEAU

\begin{tabular}{|c|c|c|c|c|c|c|c|c|c|}
\hline ROW & (BASIS) & & P1 & R1 & E1 & P2 & $\mathbf{R} 2$ & E2 & \\
\hline 1 & & ART & 0.000 & 0.000 & 0.000 & 0.000 & 0.000 & 0.000 & \\
\hline 2 & $\mathrm{R} 1$ & & 1.000 & 1.000 & 1.000 & 0.000 & 0.000 & 0.000 & \\
\hline 3 & P2 & & 1.000 & 0.000 & 0.000 & 1.000 & 0.000 & 0.000 & \\
\hline 4 & & SLK & & 4 & 0.000 & 0.000 & 0.000 & 0.000 & 0.000 \\
\hline 5 & P3 & & 0.000 & 0.000 & 0.000 & 0.000 & 0.000 & 0.000 & \\
\hline 6 & $\mathrm{R} 2$ & & -1.000 & 0.000 & -1.000 & 0.000 & 1.000 & 0.000 & \\
\hline 7 & E2 & & 0.000 & 0.000 & 1.000 & 0.000 & 0.000 & 1.000 & \\
\hline 8 & & SLK & & 8 & 0.150 & $\begin{array}{l}0.000 \\
0.000\end{array}$ & 0.000 & 0.000 & \\
\hline 9 & & SLK & & 9 & -0.500 & 0.000 & -0.500 & 0.000 & 0.000 \\
\hline 10 & & SLK & & 10 & -0.200 & 0.000 & -0.200 & 0.000 & 0.000 \\
\hline 11 & & SLK & & 11 & 0.000 & 0.000 & 0.150 & 0.000 & 0.000 \\
\hline 12 & & SLK & & 12 & 0.000 & 0.000 & 0.200 & 0.000 & 0.000 \\
\hline 13 & & SLK & & 13 & -0.050 & 0.000 & 0.000 & 0.000 & 0.000 \\
\hline
\end{tabular}




\begin{tabular}{|c|c|c|c|c|c|c|c|}
\hline ROW & P3 & R3 & E3 & SLK 2 & SLK 3 & SLK 4 & SLK 5 \\
\hline 1 & 0.000 & 0.000 & 0.000 & 9.000 & 3.000 & 0.000 & 35.000 \\
\hline 2 & 0.000 & 0.000 & 0.000 & 1.000 & 0.000 & 0.000 & 0.000 \\
\hline 3 & 0.000 & -1.000 & -1.000 & 1.000 & 1.000 & 0.000 & 0.000 \\
\hline 4 & 0.000 & 0.000 & 0.000 & 1.000 & 1.000 & 1.000 & 1.000 \\
\hline 5 & 1.000 & 1.000 & 1.000 & -1.000 & -1.000 & 0.000 & -1.000 \\
\hline 6 & 0.000 & 1.000 & 0.000 & -1.000 & 0.000 & 0.000 & 0.000 \\
\hline 7 & 0.000 & 0.000 & 1.000 & 0.000 & 0.000 & 0.000 & 0.000 \\
\hline 8 & 0.000 & 0.100 & 0.100 & -0.100 & -0.100 & 0.000 & -0.050 \\
\hline 9 & 0.000 & 1.000 & 0.000 & -0.500 & 0.000 & 0.000 & 0.000 \\
\hline 10 & 0.000 & 0.000 & 0.000 & -0.200 & 0.000 & 0.000 & 0.000 \\
\hline 11 & 0.000 & 0.000 & -0.100 & 0.000 & 0.000 & 0.000 & 0.000 \\
\hline 12 & 0.000 & 0.000 & 0.000 & 0.000 & 0.000 & 0.000 & 0.000 \\
\hline 13 & 0.000 & 0.100 & 0.100 & -0.100 & -0.100 & 0.000 & -0.030 \\
\hline ROW & SLK 6 & SLK 7 & SLK 8 & SLK 9 & SLK 10 & SLK 11 & SLK 12 \\
\hline 1 & 35.000 & 35.000 & 0.000 & 0.000 & 0.000 & 0.000 & 0.000 \\
\hline 2 & 0.000 & 0.000 & 0.000 & 0.000 & 0.000 & 0.000 & 0.000 \\
\hline 3 & 1.000 & 1.000 & 0.000 & 0.000 & 0.000 & 0.000 & 0.000 \\
\hline 4 & 1.000 & 1.000 & 0.000 & 0.000 & 0.000 & 0.000 & 0.000 \\
\hline 5 & -1.000 & -1.000 & 0.000 & 0.000 & 0.000 & 0.000 & 0.000 \\
\hline 6 & -1.000 & 0.000 & 0.000 & 0.000 & 0.000 & 0.000 & 0.000 \\
\hline 7 & 0.000 & -1.000 & 0.000 & 0.000 & 0.000 & 0.000 & 0.000 \\
\hline 8 & -0.100 & -0.100 & 1.000 & 0.000 & 0.000 & 0.000 & 0.000 \\
\hline 9 & -0.500 & 0.000 & 0.000 & 1.000 & 0.000 & 0.000 & 0.000 \\
\hline 10 & -0.200 & 0.000 & 0.000 & 0.000 & 1.000 & 0.000 & 0.000 \\
\hline 11 & 0.000 & -0.100 & 0.000 & 0.000 & 0.000 & 1.000 & 0.000 \\
\hline 12 & 0.000 & -0.100 & 0.000 & 0.000 & 0.000 & 0.000 & 1.000 \\
\hline 13 & -0.100 & -0.100 & 0.000 & 0.000 & 0.000 & 0.000 & 0.000 \\
\hline
\end{tabular}




\begin{tabular}{ccc}
\hline ROW & \multicolumn{2}{c}{ SLK 13 } \\
\hline 1 & $0.00 \mathrm{E}+00$ & $-0.19 \mathrm{E}+07$ \\
2 & 0.000 & 15000.000 \\
3 & 0.000 & 0.000 \\
4 & 0.000 & 10000.000 \\
5 & 0.000 & 14000.000 \\
6 & 0.000 & 7000.000 \\
7 & 0.000 & 25000.000 \\
8 & 0.000 & 700.000 \\
9 & 0.000 & 3500.000 \\
10 & 0.000 & 1400.000 \\
11 & 0.000 & 2500.000 \\
12 & 0.000 & 2500.000 \\
13 & 1.000 & 420.000 \\
\hline
\end{tabular}

\section{Data envelopment analysis and linear programming}

\subsection{Modeling of ranking units using Data Envelopment Analysis (DEA)}

Data envelopment analysis (DEA), occasionally called frontier analysis, was first put forward by Charnes, Cooper and Rhodes in 1978. It is a performance measurement technique which, as we shall see, can be used for evaluating the relative efficiency of decision-making units (DMU's) in organizations. Here a DMU is a distinct unit within an organization that has flexibility with respect to some of the decisions it makes, but not necessarily complete freedom with respect to these decisions.

Examples of such units to which DEA has been applied are: banks, police stations, hospitals, tax offices, prisons, defense bases (army, navy, air force), schools and university departments. Note here that one advantage of DEA is that it can be applied to non-profit making organizations.

Since the technique was first proposed much theoretical and empirical work has been done. Many studies have been published dealing with applying DEA in real-world situations. Obviously there are many more unpublished studies, e.g. done internally by companies or by external consultants.

We will initially illustrate DEA by means of a small example. More about DEA can be found on line using Google: "Data Envelopment Analysis". Note here that much of what you will 
see below is a graphical (pictorial) approach to DEA. This is very useful if you are attempting to explain DEA to those less technically qualified (such as many you might meet in the military or management world). There is a mathematical approach to DEA that can be adopted however. We will present the single measure first to demonstrate the idea and then move to multiple measures and use linear programming methodology from our course.

Example 1. Ranking Banks

Consider a number of bank branches. For each branch we have a single output measure (number of personal transactions completed) and a single input measure (number of staff).

The data we have is as follows:

\begin{tabular}{ccc}
\hline Branch & Personal transactions ('000s) & Number of staff \\
\hline Branch 1 & 125 & 18 \\
Branch 2 & 44 & 16 \\
Branch 3 & 80 & 17 \\
Branch 4 & 23 & 11 \\
\hline
\end{tabular}

For example, for the Branch 2 in one year, there were 44,000 transactions relating to personal accounts and 16 staff members were employed.

How then can we compare these branches and measure their performance using this data?

\section{Ratios}

A commonly used method is ratios. Typically we take some output measure and divide it by some input measure. Note the terminology here, we view branches as taking inputs and converting them (with varying degrees of efficiency, as we shall see below) into outputs.

For our bank branch example we have a single input measure, the number of staff, and a single output measure, the number of personal transactions. Hence we have:

\begin{tabular}{cc}
\hline Branch & Personal transactions per staff member ('000s) \\
\hline Branch 1 & 6.94 \\
Branch 2 & 2.75 \\
Branch 3 & 4.71 \\
Branch 4 & 2.09 \\
\hline
\end{tabular}

Here we can see that Branch1 has the highest ratio of personal transactions per staff member, whereas Branch 4 has the lowest ratio of personal transactions per staff member. 
As Branch 1 has the highest ratio of 6.94 we can compare all other branches to it and calculate their relative efficiency with respect to Branch 1 . To do this we divide the ratio for any branch by 6.94 (the value for Croydon) and multiply by 100 to convert to a percentage. This gives:

\begin{tabular}{cc}
\hline Branch & Relative efficiency \\
\hline Branch 1 & $100(6.94 / 6.94)=100 \%$ \\
Branch 2 & $100(2.75 / 6.94)=40 \%$ \\
Branch 3 & $100(4.71 / 6.94)=68 \%$ \\
Branch 4 & $100(2.09 / 6.94)=30 \%$ \\
\hline
\end{tabular}

The other branches do not compare well with Branch 1, so are presumably performing less well. That is, they are relatively less efficient at using their given input resource (staff members) to produce output (number of personal transactions).

We could, if we wish, use this comparison with Branch 1 to set targets for the other branches.

For example we could set a target for Branch 4 of continuing to process the same level of output but with one less member of staff. This is an example of an input target as it deals with an input measure.

An example of an output target would be for Branch 4 to increase the number of personal transactions by $10 \%$ (e.g. by obtaining new accounts).

Plainly, in practice, we might well set a branch a mix of input and output targets which we want it to achieve. We can use linear programming.

\subsection{Linear Programming example of DEA}

Example 2. Ranking banks with linear programming

Typically we have more than one input and one output. For the bank branch example suppose now that we have two output measures (number of personal transactions completed and number of business transactions completed) and the same single input measure (number of staff) as before.

The data we have is as follows:

\begin{tabular}{cccc}
\hline Branch & $\begin{array}{c}\text { Personal } \\
\text { transactions } \\
\text { ('000s) }\end{array}$ & $\begin{array}{c}\text { Business } \\
\text { transactions } \\
\text { ('000s) }\end{array}$ & $\begin{array}{c}\text { Number of } \\
\text { staff }\end{array}$ \\
\hline Branch 1 & 125 & 50 & 18 \\
Branch 2 & 44 & 20 & 16 \\
Branch 3 & 80 & 55 & 17 \\
\hline
\end{tabular}


We start be scaling (via ratios) the inputs and outputs to reflect the ratio of 1 unit.

\begin{tabular}{|c|c|c|c|}
\hline Branch & $\begin{array}{l}\text { Personal transactions } \\
\text { ('000s) }\end{array}$ & $\begin{array}{l}\text { Business transactions } \\
\text { ('000s) }\end{array}$ & Per employee or staff \\
\hline Branch 1 & $125 / 18=6.94$ & $50 / 18=2.78$ & $18 / 18=1$ \\
\hline Branch 2 & $44 / 16=2.75$ & $20 / 16=1.25$ & $16 / 16=1$ \\
\hline Branch 3 & $80 / 17=4.71$ & $55 / 17=3.24$ & $17 / 17=1$ \\
\hline Branch 4 & $23 / 11=2.09$ & $12 / 11=1.09$ & $11 / 11=1$ \\
\hline
\end{tabular}

Pick a DMU to maximize: E1, E2, E3, or E4

Let $W 1$ and $W 2$ be the personal and business transactions at branch

In this example we choose to maximize branch two, E2.

Here is the LP formulation for this DEA problem:

Maximize E2

Subject to

$E 1=6.94 W 1+2.78 W 2$

$E 2=2.75 W 1+1.25 W 2$

$E 3=4.71 W 1+3.24 W 2$

$E 4=2.09 W 1+1.09 W 2$

$E 1 \leq 1$

$E 2 \leq 1$

$E 3 \leq 1$

$E 4 \leq 1$

Now, what did we learn from this. If we ranked ordered the branches on efficiency performance of our inputs and outputs, we find

\begin{tabular}{ll}
\hline Branch 1 & $100 \%$ \\
Branch 3 & $100 \%$ \\
Branch 2 & $43.2 \%$ \\
Branch 4 & $36.2 \%$ \\
\hline
\end{tabular}


We know we need to improve on branch 2 and branch 4 performances while not losing our efficiency in branches 1 and 3 . A better interpretation could be that the practices and procedures used by the other branches were to be adopted by Branch 4, they could improve their performance.

This invokes issues of highlighting and disseminating examples of best practices. Equally there are issues relating to identification of poor practices.

In DEA the concept of the reference set can be used to identify best performing branches with which to compare poorly performing branches. If you use this procedure, use it wisely.

\section{Author details}

William P. Fox ${ }^{1}$ and Fausto P. Garcia ${ }^{2}$

1 Naval Postgraduate School, USA

2 Universidad Castilla-La Mancha, Spain

\section{References}

[1] Apaiah, R. \& E. Hendrix ((2006). Linear programming for supply chain design: A case on Novel protein foods. Ph.D. Thesis, Wageningen University, Netherlands.

[2] Balakrishnan, N. B, \& Render, R. Stair. ((2007). Managerial Decision Making, 2nd Ed. Saddle River, NJ: Prentice Hall.

[3] Bazarra Mokhtar S. J.J. Jarvis, and H. D. SheralliLinear Programming and Network Flows, New York. John Wiley \& Sons, (1990).

[4] EckerJoseph and M. Kupperschmid, Introduction to Operations Research, John Wiley and Sons, (1988).

[5] Fox, W. P. (2012). Mathematical Modeling with Maple. Boston, MA: Cengage Publishers.

[6] Giordano, F, Fox, W, Horton, S, \& Weir, M. (2009). A First Course in Mathematical Modeling, 4th Ed. Belmont, CA: Brooks-Cole.

[7] Hiller Fredrick S and Gerald J. LibermanIntroduction to Mathematical Programming, McGraw Hill Publishing Company, (1990).

[8] Winston Wayne L. Introduction to Mathematical Programming Applications and Algorithms, 4th Edition. Belmont, CA. Duxbury Press. (2002). 